\title{
Monetary and Exchange Rate Dynamics During Disinflation: An Empirical Analysis
}

A. Javier Hamann, Andrés Arias, and Lei Zhang 


\title{
IMF Working Paper
}

Policy Development and Review Department

\section{Monetary and Exchange Rate Dynamics During Disinflation: An Empirical Analysis}

\author{
Prepared by A. Javier Hamann, Andrés Arias, and Lei Zhang ${ }^{1}$ \\ Authorized for distribution by Atish R. Ghosh
}

February 2005

\begin{abstract}
This Working Paper should not be reported as representing the views of the IMF. The views expressed in this Working Paper are those of the author(s) and do not necessarily represent those of the IMF or IMF policy. Working Papers describe research in progress by the author(s) and are published to elicit comments and to further debate.

Based on the observed behavior of monetary aggregates and exchange rates, we classify inflation-stabilization episodes into two categories: de facto exchange rate-based stabilizations (ERBS) and non-ERBS. Unlike the standard de jure ERBS studied in the literature, de facto ERBS encompass cases in which the central bank intervenes in the foreign exchange market but does not preannounce the use of an exchange rate anchor. The number of the de facto ERBS is twice as large as that of de jure ERBS. Output dynamics during disinflation do not differ significantly between these two groups. We conclude that empirical studies on the effects of exchange rate anchors must seek to disentangle the effects of their announcement from those related to their role in the remonetization process.
\end{abstract}

JEL Classification Numbers: E31, E63, F41

Keywords: Inflation stabilization, nominal anchor, exchange rate-based stabilization

Author(s) E-Mail Address: ahamann@imf.org; aarias@minagricultura.gov.col; zlei@clemson.edu

\footnotetext{
${ }^{1}$ Independent Evaluation Office, IMF; Ministry of Agriculture, Colombia; and Clemson University, respectively. This paper was prepared while the authors were in the Policy Review Division in the Policy Development and Review Department. The authors thank Tim Lane, Marc Hofstetter, and participants in the 9th Annual Meeting of the Latin American and Caribbean Economic Association (San José, Costa Rica, November 4-6, 2004) for helpful comments and suggestions.
} 
I. Introduction 3

II. Stabilization Episodes: Sample Selection and Key Features ..... .5

A. Parameterization and Episode Identification .....................................................6

B. Stabilization Episodes: History, Duration, and Speed ........................................

III. Monetary and Exchange Rate Dynamics and the Role of the Nominal Anchor: Some Simple Experiments

A. Monetary and Exchange Rate Dynamics in ERBS and Non-ERBS ........................10

B. Classifying Episodes with Cluster Analysis......................................................... 12

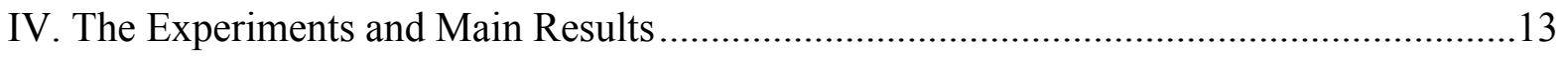

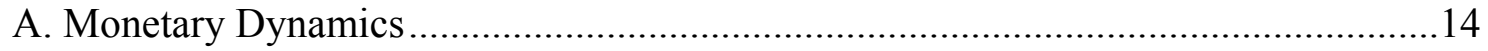

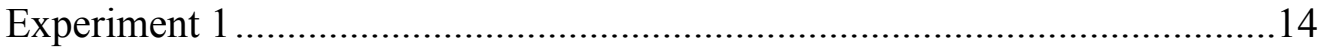

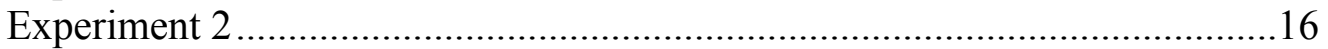

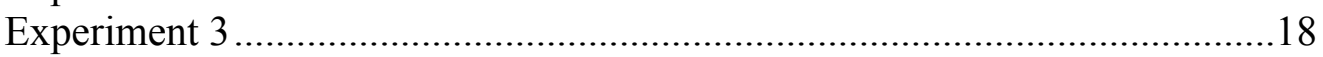

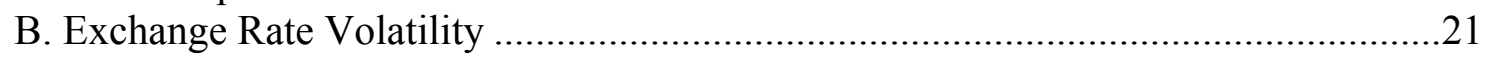

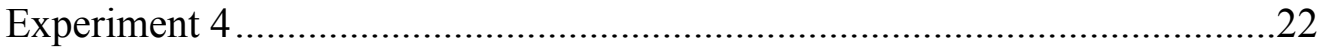

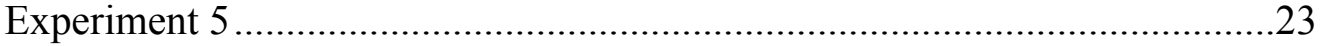

V. De Facto ERBS, De Jure ERBS, and Output Dynamics: Some Final Observations ..........24

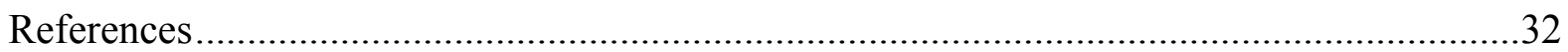

Figures

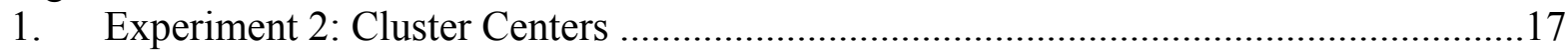

2. Experiment 3: Cluster Centers ........................................................................20

3. De Facto Classification: Growth in GDP Per Capita During Disinflation ...................27

4. De Jure Classification: Growth in GDP Per Capita During Disinflation .....................28

5. De Facto Classification: Output Gaps During Disinflation ......................................29

6. De Jure Classification: Output Gaps During Disinflation ........................................30

Tables

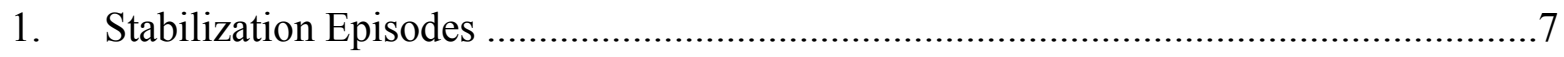

2. Exchange Rate-Based Episodes: Historical Facts ........................................... 9

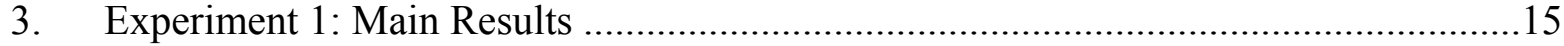

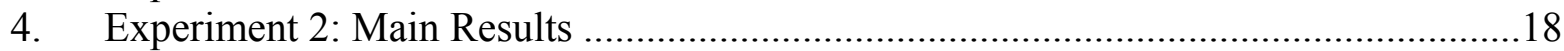

5. Experiment 3: Main Results .............................................................................21

6. Experiment 4: Main Results ............................................................................22

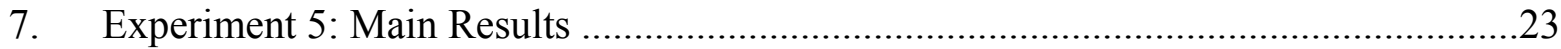

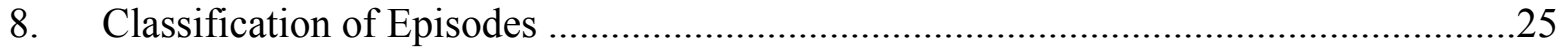

Appendix Table

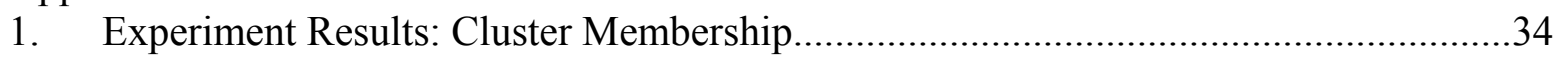




\section{"Never argue with the data!" \\ -Sheen, in "Jimmy Neutron, Boy Genius"}

\section{INTRODUCTION}

In an insightful paper, Kiguel and Liviatan (1992) recognized several empirical regularities that arise when inflation is brought down from chronically high levels using a strategy based on the preannouncement of a path for the nominal exchange rate. Subsequently, a substantial amount of research was devoted to further identifying the distinctive features of this exchange rate-based stabilization (ERBS) syndrome and, later, to explaining it. ${ }^{2}$ One of the features of this "syndrome" is a boom-bust cycle in output—see, for example, Hoffmaister and Végh (1996).

The notion that disinflation from chronically high (but not hyper-) inflation could be, at least initially, expansionary ran counter to the commonly held view that demand restraint-based stabilization plans unavoidably entail output costs - see, for example, Gordon (1982). ${ }^{3}$ Nonetheless, some years before the ERBS-syndrome literature began to develop, Fischer (1986) had shown that the use of an exchange rate anchor could allow a country to avoid output losses even in the presence of sticky prices and/or wages. Using a reduced-form model, Fischer compared the real effects of a money-based stabilization (MBS) with those of an ERBS. Under a MBS, the increase in money demand caused by lower expected inflation is associated with a recession needed to generate a decline in (sticky) domestic prices and, thus, an equilibrating increase in the real stock of money. Under an ERBS, the increased money demand is met by a larger nominal stock of money, achieved through a surplus in the balance of payments; no recession is needed. Importantly, in this model the preannouncement of the peg is immaterial - unlike in the literature on the ERBS syndrome, where agents' expectations about the future path of the exchange rate and the eventual fate of the stabilization plan are a key driver of domestic demand and output. It could be argued, then, that a key difference between Fischer's model and those associated with the subsequent ERBS literature regarding output dynamics is that the former focuses on the channel through which remonetization takes place, whereas the latter relies crucially on the assumed response by economic agents to the announcement of a disinflation strategy. As discussed later on, one thing is clear, however: stabilizations can be unambiguously expansionary when an exchange rate anchor is used, even if this is not preannounced. We will refer to these regimes as de facto - as opposed to de jure-ERBS, in line with the recent literature on the classification of exchange rate regimes. Pure MBS, in contrast, should be expected to be contractionary, at least initially.

\footnotetext{
${ }^{2}$ Other work aimed at identifying the ERBS syndrome includes Végh (1992) and Calvo and Végh (1994). Rebelo and Végh (1996) assess quantitatively the explanatory power of several theories put forth to explain the ERBS syndrome.

${ }^{3}$ Following Sargent (1982), the possibility of an abrupt end to hyperinflations at little or no output cost became increasingly accepted. But this would not be the case for nonhyperinflations, where inertia in wages and/or prices would lead to output losses.
} 
Unfortunately, empirical studies on the effects of disinflation on output have generally focused on the role of alternative preannounced anchors and have not accounted for the possibility of de facto ERBS. Furthermore, since many of them have tended to identify as MBS all those stabilizations which were not clear cases of de jure ERBS, their claims about distinctive characteristics associated with the use of an exchange rate anchor may be biased. Further, this bias could well be directly related to the presence of de facto ERBS wrongfully classified as MBS in the sample. Perhaps for this reason, the findings of these studies are mixed: Easterly (1996), Gould (2001), and Hamann (2001) find, on the one hand, that disinflations from chronically high levels are accompanied by an acceleration in output growth, irrespective of whether the exchange rate is the anchor. Fischer, Sahay and Végh (2002), on the other hand, find evidence that ERBS are distinctively expansionary.

Uribe (1999) provides a possible explanation for the mixed empirical record. Using an extension of the model developed by Calvo and Végh (1994), he compares the dynamics of real variables and estimates the welfare effects of three alternative disinflation programs: (i) an ERBS; (ii) a MBS; and (iii) a stabilization plan based on the preannouncement of a monetary rule that also allows for a one-time increase in the stock of money at the onset of the stabilization (a strategy Uribe terms money-based-cum-reliquification, or MBRS). When these programs are designed to succeed only temporarily, the MBS produces an initial (and large) recession, while the ERBS generates an initial boom followed by a recession that starts when the program is abandoned. The welfare cost of a temporary MBS is much larger than that of a temporary ERBS. Most interestingly, however, is the finding that the dynamics of real variables (and the welfare effects) of a MBRS are very similar to those of an ERBS. This suggests that if stabilization is anchored in money, a once-and-for-all increase in the money stock eliminates the need for a recession. Uribe concludes that this may explain why most empirical studies that purport to compare the effects of ERBS with pure MBS have great difficulties in finding significantly different output effects: pure MBS are rarely implemented.

A key issue in Uribe's perfect-foresight model is that the way in which the one-time reliquification takes place is of no relevance to the results. In practice, however, things are likely to be more complicated. Countries aiming at stopping a very high inflation typically face serious credibility issues. For this reason, it may be difficult for them to carry out a onetime large expansion in base money through purchases of government paper or through a direct loan to the government or the banking system. These actions could raise fears that the government is returning to its old practice of relying on seigniorage. An alternative (and possibly less costly, in terms of credibility) way of achieving a one-time remonetization is outright purchases of foreign exchange. A direct implication of this is that governments that, for whatever reasons, avoid announcing an exchange rate anchor (e.g., avoid a de jure ERBS) and try to prevent an initial credit crunch by engaging in purchases of foreign exchange will effectively be putting in place some form of exchange rate anchor. In other words, a likely practical implication of Uribe's findings is that there are good reasons to suspect that stabilization programs where an exchange rate anchor is not preannounced may still entail the use of a de facto exchange rate anchor.

The purpose of this study is to reexamine the issue of whether the use of an exchange rate anchor during disinflation prevents a recession, but focusing on de facto ERBS rather than on 
de jure ERBS, as has been done until now. To this end, we first develop a simple methodology for classifying stabilizations based on the actual behavior of a set of variables (base money and its components, gross international reserves, and exchange rate volatility) during disinflation. We then compare output dynamics among the resulting groups. Out of a sample of 53 episodes, we manage to classify 44. Of these, 17 are de jure ERBS; however, we find that 32 episodes can be considered de facto ERBS. ${ }^{4}$ Although we find that output growth is particularly strong in the first year of disinflation in de jure ERBS, we also find no evidence in support of the notion that stabilizations are contractionary when a preannounced path for the exchange rate is not part of the program. Growth during disinflation is positive in the bigger group of de jure ERBS but also in non-ERBS. A relatively marked deceleration in post-stabilization growth is observed in the de jure ERBS and the de facto non-ERBS. But in both cases, this result seems to be affected by initial conditions: growth tends to decelerate after output gaps swing into positive territory. A more systematic assessment of poststabilization growth is beyond the scope of this paper, but we believe that our results can be used to help disentangle the effects of an exchange rate anchor (i.e., those associated with the announcement from those related to its role in the remonetization process).

\section{Stabilization EPISOdes: SAMPLe Selection AND Key Features}

The inflation stabilization episodes used in this study were selected by applying a simple set of rules to monthly year-on-year inflation rates for all non-transition economies for which data were available (for a sufficiently long period of time) in the IMF's International Financial Statistics. ${ }^{5,6}$ The resulting panel contains observations for 140 countries covering the period January 1960 to July 2001.

A stabilization episode is defined as a period of substantial decline in inflation from a relatively high, but not temporary, level. Thus, the first rule required for identification of a stabilization was that immediately before it began, inflation had to remain above a threshold value $(\bar{\pi})$ for at least 24 months. If this first condition is met, a stabilization episode is said to begin at time $T$ if two additional conditions are met simultaneously: (i) a significant decline in inflation begins in that month, specifically: inflation in month $T$ cannot exceed a fraction $(1-\alpha)$ of the rate prevailing 12 months before - a rate which will be called the 'reference rate' or $\pi^{\mathrm{r}}$; and (ii) this is followed by a period of at least 11 additional consecutive months in which inflation does not revert back to a relatively high level, which need not coincide with the initial threshold $(1-\alpha) \pi^{\mathrm{r}}$. In fact, in order to leave room for a moderate increase in inflation following the initial decline, we allow inflation to remain below (1- $\beta) \pi^{\mathrm{r}}$ during the 11 months following $T$ and focus on cases where $\alpha \geq \beta$. Note that the

\footnotetext{
${ }^{4}$ Twelve of the 17 de jure ERBS are classified as de facto ERBS.

${ }^{5}$ This excludes transition economies in Eastern Europe; the Baltics and other republics of the former Soviet Union; the Lao People's Democratic Republic; Vietnam; and Cambodia.

${ }^{6}$ We used year-on-year monthly inflation rates, rather than annualized monthly rates, in order to avoid or dampen seasonal patterns and occasional spikes in monthly inflation rates.
} 
lower the values of $\alpha$ or $\beta$ the looser the criteria for selecting inflation stabilization episodes: a low $\alpha$ means that only a small initial decline in inflation is required, whereas a low $\beta$ would mean that, following the initial decline, inflation can approach $\pi^{\mathrm{r}}$. Formally, $T$ is a stabilization date if the three following conditions are met:

$$
\begin{aligned}
& \text { (i) } \pi_{\mathrm{t}} \geq \bar{\pi} \text { for } \mathrm{t}=T-24, T-23, \ldots T-1 \text {; } \\
& \text { (ii) } \pi_{T} \leq(1-\alpha) \pi^{\mathrm{r}} \text { where } \pi^{\mathrm{r}}=\pi_{\mathrm{T}-12} \\
& \text { (iii) } \pi_{\mathrm{t}} \leq(1-\beta) \pi^{\mathrm{r}} \text { for } \mathrm{t}=T+1, \ldots, T+11 .
\end{aligned}
$$

\section{A. Parameterization and Episode Identification}

Following Bruno and Easterly (1995), Easterly (1996) and Hamann (2001) we set $\bar{\pi}$ initially at 40 percent. Also in line with those studies, we repeated the exercise lowering $\bar{\pi}$ to 35 and 30 percent in order to determine how many episodes could be lost at the margin ("near misses"). Several combinations of $\alpha$ and $\beta$ were also tried and we eventually settled for a sample of stabilization episodes obtained with $\bar{\pi}=30 \%$ and $\alpha=\beta=0.25$.

A mechanical application of rules (i)-(iii) yielded initially 67 stabilization episodes. However, 11 of these were dropped because they did not represent independent stabilizations, but were part of an ongoing one: in six cases the stabilization dates were simply too close (almost consecutive) to a previously identified date for a given country, and in five other cases either the existing literature or IMF country reports led us to the conclusion that they were part of an ongoing stabilization program. Three additional episodes (Uganda, December 1988; Nicaragua, December 1989; Zambia, December 1993) had to be excluded due to lack of data on monetary and international reserves, which are needed for the tests carried out in the following sections. As a result, our final sample comprises 53 episodes, shown in the first two columns of Table 1.

The determination of whether a stabilization episode should be considered a formal or de jure ERBS was also based on the existing literature and/or IMF country reports. De jure ERBS encompass all cases in which a path for the nominal exchange rate or a specific rule for it (including, for example, a pre-announced band) consistent with a deceleration in inflation had been announced at the outset of the program. On this basis, 17 of the 53 episodes can be characterized as de jure ERBS (Table 2), although the resulting classification is not without some problems. One of these problems has to do with the starting date of stabilizations. Since the stabilization episodes shown in Table 1 were selected and dated on the basis of numerical rules applied only to the actual inflation rate, the resulting date need not coincide with the historical date in which the de jure ERBS was initially implemented. Table 2 compares the historical dates of each of the 17 ERBS with those identified using the selection rules. Only Argentina, July 1990, is classified as a de jure ERBS even though the actual adoption of an exchange rate anchor preceded the stabilization date produced by the numerical rules (the

\footnotetext{
${ }^{7}$ Only a handful of additional episodes were picked up by lowering $\bar{\pi}$ to 30 percent.
} 
Table 1. Stabilization Episodes

\begin{tabular}{|c|c|c|c|c|}
\hline & $\begin{array}{l}\text { Stabilization } \\
\text { date } 1 /\end{array}$ & History 2/ & Duration 2/ & Speed \\
\hline 1 Angola & $1996-11$ & 70 & 53 & 1.00 \\
\hline 2 Argentina 1 & $1973-11$ & 30 & 14 & 0.25 \\
\hline 3 Argentina 2 & $1977-02$ & 27 & 76 & 1.00 \\
\hline 4 Argentina 3 & $1980-02$ & 63 & 22 & 0.25 \\
\hline 5 Argentina 4 & $1985-11$ & 132 & 42 & 1.00 \\
\hline 6 Argentina 5 & $1990-07$ & 188 & 130 & 1.00 \\
\hline 7 Bolivia & 1986-02 & 47 & 184 & 1.00 \\
\hline 8 Brazil 1 & $1965-06$ & 46 & 174 & 1.00 \\
\hline 9 Brazil 2 & $1991-01$ & 183 & 32 & 1.00 \\
\hline 10 Brazil 3 & $1994-11$ & 229 & 79 & 0.75 \\
\hline 11 Chile 1 & $1965-02$ & 24 & 87 & 0.08 \\
\hline 12 Chile 2 & $1975-02$ & 33 & 316 & 0.67 \\
\hline 13 Congo, Dem. Rep. 1 & $1977-07$ & 24 & 16 & 0.08 \\
\hline 14 Congo, Dem. Rep. 2 & $1995-01$ & 111 & 38 & 1.00 \\
\hline 15 Costa Rica & $1983-05$ & 24 & 215 & 0.25 \\
\hline 16 Dominican Republic & 1991-09 & 43 & 103 & 0.17 \\
\hline 17 Ecuador 1 & 1989-11 & 24 & 34 & 0.92 \\
\hline 18 Ecuador 2 & 1993-09 & 70 & 66 & 0.42 \\
\hline 19 Ghana 1 & $1978-07$ & 35 & 31 & 0.08 \\
\hline 20 Ghana 2 & 1996-11 & 24 & 55 & 0.42 \\
\hline 21 Guinea-Bissau 1 & 1993-08 & 29 & 22 & 0.17 \\
\hline 22 Guinea-Bissau 2 & 1997-09 & 30 & 43 & 0.08 \\
\hline 23 Iceland 1 & $1976-01$ & 24 & 27 & 0.75 \\
\hline 24 Iceland 2 & $1984-03$ & 77 & 207 & 0.33 \\
\hline 25 Israel & $1985-10$ & 111 & 187 & 0.83 \\
\hline 26 Lebanon & $1988-04$ & 39 & 81 & 0.83 \\
\hline 27 Malawi & 1996-09 & 24 & 56 & 0.08 \\
\hline 28 Mexico 1 & 1984-01 & 24 & 29 & 0.92 \\
\hline 29 Mexico 2 & 1988-09 & 80 & 152 & 0.50 \\
\hline 30 Mozambique & $1996-10$ & 81 & 40 & 0.17 \\
\hline 31 Nicaragua & 1991-08 & 84 & 101 & 0.67 \\
\hline 32 Nigeria 1 & $1990-01$ & 24 & 27 & 0.08 \\
\hline 33 Nigeria 2 & $1995-12$ & 45 & 63 & 0.58 \\
\hline 34 Peru 1 & 1986-04 & 117 & 20 & 0.75 \\
\hline 35 Peru 2 & $1991-07$ & 180 & 118 & 1.00 \\
\hline 36 Sierra Leone 1 & $1988-01$ & 63 & 159 & 0.33 \\
\hline 37 Sierra Leone 2 & $1992-08$ & 44 & 65 & 0.67 \\
\hline 38 Sudan 1 & $1995-01$ & 87 & 14 & 0.08 \\
\hline 39 Sudan 2 & $1997-04$ & 114 & 37 & 0.50 \\
\hline 40 Suriname & $1995-08$ & 41 & 65 & 0.50 \\
\hline 41 Syrian Arab Rep. & 1988-06 & 24 & 151 & 0.08 \\
\hline 42 Turkey 1 & $1981-02$ & 41 & 158 & 0.33 \\
\hline 43 Turkey 2 & $1986-02$ & 30 & 21 & 0.17 \\
\hline 44 Turkey 3 & $1995-05$ & 141 & 28 & 0.08 \\
\hline 45 Turkey 4 & $1998-12$ & 184 & 30 & 0.42 \\
\hline 46 Uruguay 1 & $1968-12$ & 62 & 47 & 0.50 \\
\hline 47 Uruguay 2 & $1973-11$ & 25 & 12 & 0.08 \\
\hline 48 Uruguay 3 & $1975-11$ & 49 & 45 & 0.17 \\
\hline 49 Uruguay 4 & $1980-11$ & 109 & 36 & 1.00 \\
\hline 50 Uruguay 5 & 1991-09 & 104 & 116 & 1.00 \\
\hline 51 Venezuela 1 & $1990-11$ & 24 & 45 & 0.42 \\
\hline 52 Venezuela 2 & $1997-05$ & 63 & 47 & 1.00 \\
\hline 53 Zambia & $1990-08$ & 55 & 18 & 0.42 \\
\hline
\end{tabular}

Sources: International Monetary Fund, International Financial Statistics (various issues); and authors' calculations.

1/ Dates shown indicate the year followed by the month.

2/ In months. 
currency board was adopted in April of 1991); this, however, has no material consequences for the analysis carried out later on. Another problem has to do with the fact that the group of de jure ERBS constitutes a fairly heterogeneous class. In some cases there is a clearly preannounced path for the nominal exchange rate (such as the Southern Cone "tablita" experiments). In others cases, the strategies were more flexible and entailed: discrete devaluations (Iceland, March 1984; Israel, October 1985); less than perfectly clear (Ecuador, September 1993) or fairly loose (Turkey, May 1995). This heterogeneity does have consequences for the work carried out in the following sections, as explained there.

\section{B. Stabilization Episodes: History, Duration, and Speed}

As a by-product of the selection of each episode we calculated three variables that could shed some light on key characteristics of the stabilization process. The first one, termed history is the total number of consecutive months in which year-on-year inflation rates exceeded the threshold $\bar{\pi}$ prior to stabilization. By construction, this variable will score at least 24 for each episode. The second variable, duration, is the total number of consecutive months following (and including) the initial month of the stabilization episode in which year-on-year inflation rates stayed below (1- $\beta) \pi^{\mathrm{r}}$. Duration is, thus, taken as a rough measure of the success of a stabilization attempt. Also by construction, this variable will score at least 12 in each episode.

As discussed earlier, any two or more consecutive stabilization months picked by our rules are deemed part of the same stabilization episode. However, we interpret the mechanical identification of consecutive stabilization months as indicative of the speed of disinflation: if many consecutive stabilization months are picked up by the rule, this means that inflation is falling at, at least, the same pace as it did when stabilization started. Hence, a third variable called speed is constructed, which shows how many consecutive stabilization months are identified for each episode in the 12 months following - and including - the first month of the stabilization episode (i.e., how many times rules (i)-(iii) were met following the initial identification of a stabilization episode). This variable is normalized by 12 to obtain values between 0 and 1 . Note that, by construction, this variable will always score at least 1/12 for each episode.

Columns 3, 4 and 5 of Table 1 present the values of history, duration and speed for each episode.

\section{Monetary And EXchange Rate Dynamics AND THE Role of THE Nominal ANCHOR: SOME SIMPLE EXPERIMENTS}

In this chapter we produce a data-driven classification of the 53 stabilization episodes identified in Section II. The classification is based on the identification of distinctive patterns in the behavior of key macroeconomic variables that allow us to determine whether the exchange rate was used as an anchor in the stabilization plans, irrespective of whether this was announced or not. As a next step, we verify whether the group of stabilizations in which the exchange rate was used as an anchor de facto, coincides with de jure classification. Finally, we analyze differences in history, duration and speed across both groups. 
Table 2. Exchange Rate-Based Episodes: Historical Facts

\begin{tabular}{|c|c|c|}
\hline Episode & $\begin{array}{l}\text { Stabilizati } \\
\text { Date } 1 /\end{array}$ & Description of exchange rate regime during stabilization \\
\hline 1 Argentina 1 & $1973-11$ & $\begin{array}{l}\text { Broad-based reform program, including an inflation stabilization plan based on wage-price- } \\
\text { exchange rate freeze, was introduced in June } 1973 \text {. }\end{array}$ \\
\hline 2 Argentina 2 & $1977-02$ & $\begin{array}{l}\text { A program to convert the prevailing multiple exchange rate system into a dual system (with } \\
\text { separate rates for commercial and financial transactions) was introduced in April 1976. Both } \\
\text { exchange rates were fixed by the central bank with periodic adjustments. }\end{array}$ \\
\hline 3 Argentina 3 & $1980-02$ & $\begin{array}{l}\text { A "Tablita" or preannounced crawling peg system was introduced in December } 1978 \text { and } \\
\text { abandoned in February } 1981\end{array}$ \\
\hline 4 Argentina 4 & $1985-11$ & $\begin{array}{l}\text { Austral Plan. Between June } 1985 \text { and March } 1986 \text { the exchange rate was fixed. In March } 1986 \text { a } \\
\text { crawling peg system was introduced. The crawling peg system was abandoned in September } \\
\text { 1986. }\end{array}$ \\
\hline 5 Argentina 5 & $1990-07$ & $\begin{array}{l}\text { Between } 1989 \text { and March 1991, the government adopted several short-lived stabilization plans, } \\
\text { none based on an explicit exchange rate anchor. A currency board with a one-to-one parity to the } \\
\text { U.S. dollar was introduced in April 1991. The parity was abandoned in January } 2002 \text {. }\end{array}$ \\
\hline 6 Brazil 1 & $1965-06$ & $\begin{array}{l}\text { Fixed but adjustable peg introduced in March 1964. Regime ended in May } 1968 \text { with a discrete } \\
\text { devaluation followed by a system of minidevaluations. }\end{array}$ \\
\hline 7 Brazil 3 & $1994-11$ & $\begin{array}{l}\text { As part of the Real Plan introduced in July 1994, a new currency, the real, was introduced. Its } \\
\text { introduction follows that of a virtual currency that had been indexed to the U.S. dollar at a parity } \\
\text { of one to one. The new currency was allowed to fluctuate moderately: after appreciating during } \\
\text { the second half of } 1995 \text { it depreciated gradually and at a slow rate until January } 1999 \text { when the } \\
\text { currency was allowed to float. }\end{array}$ \\
\hline 8 Ecuador 2 & $1993-09$ & $\begin{array}{l}\text { As part of the adjustment program started in August 1992, the government devalued the sucre by } \\
35 \text { percent and adopted a managed exchange rate within a band. The pace of depreciation against } \\
\text { the U.S. dollar was kept significantly below domestic inflation. The system was simplified in } \\
\text { September } 1993 \text { and spreads between buying and selling rates for public transactions were } \\
\text { compressed. In December } 1994 \text { the central bank preannounced a path for the exchange rate with a } \\
\text { fluctuation band of } 4 \text { percent. The band system was abandoned in February } 1999 \text {. }\end{array}$ \\
\hline 9 Iceland 2 & $1984-03$ & $\begin{array}{l}\text { As part of the stabilization plan announced in end-May 1983, the government devalued the króna } \\
\text { by } 14.6 \text { percent and announced its intention to "keep the exchange rate stable after the } \\
\text { devaluation". }{ }^{2} \text { In October } 1983 \text { the government announced a fluctuation band of }+/-5 \text { percent for } \\
\text { 1984. Following a } 12 \text { percent devaluation in November } 1984 \text {, the government reinstated its } \\
\text { commitment to a stable exchange rate. }\end{array}$ \\
\hline 10 Israel & $1985-10$ & $\begin{array}{l}\text { On July } 1985 \text { the New Israeli Shekel was pegged to the U.S. dollar; in August } 1986 \text { the dollar peg } \\
\text { was replaced by a basket of currencies. During } 1987 \text { and } 1988 \text { the currency was devalued several } \\
\text { times. In January } 1989 \text { a band with a fixed central parity was introduced. In December } 1991 \text { a } \\
\text { crawling band was introduced. }\end{array}$ \\
\hline 11 Mexico 2 & $1988-09$ & $\begin{array}{l}\text { Following a few discrete devaluations between December } 1987 \text { and February 1988, the exchange } \\
\text { rate was fixed until December 1988. Between January } 1989 \text { and November } 1991 \text { a preannounced } \\
\text { crawling peg (vis-à-vis the U.S. dollar) was used. In November } 1991 \text { an exchange rate band was } \\
\text { introduced; it was abandoned in December } 1994 \text {. }\end{array}$ \\
\hline 12 Nicaragua & $1991-08$ & $\begin{array}{l}\text { In mid-1990 a newly elected government introduces the gold córdoba. At first used only as an } \\
\text { accounting device, the new currency was introduced gradually and coexisted for six months with } \\
\text { the old currency as legal tender (with a conversion rate of } 5 \text { million new córdobas to one gold } \\
\text { córdoba). After April } 31,1991 \text {, the gold córdoba became the sole legal currency and was pegged } \\
\text { to the United States dollar at a rate of US } \$ 1=5 \text { gold córdobas, a rate that was maintained } \\
\text { throughout } 1992 \text {. }\end{array}$ \\
\hline 13 Peru 1 & $1986-04$ & $\begin{array}{l}\text { Emergency Plan. Exchange rate fixed to the U.S. dollar in August } 1985 \text { as part of a package of } \\
\text { measures comprising also incomes policies. The parity was abandoned in December } 1986 .\end{array}$ \\
\hline 14 Turkey 3 & $1995-05$ & $\begin{array}{l}\text { In January } 1995 \text { the government begins preannouncing quarterly floors for the exchange rate. It } \\
\text { also announces a commitment to prevent significant deviations between the depreciation rate and } \\
\text { the targeted inflation rate. }\end{array}$ \\
\hline 15 Uruguay 1 & $1968-12$ & $\begin{array}{l}\text { Fixed between June } 1968 \text { and December 1971. Regime ended with a succession of large } \\
\text { devaluations. }\end{array}$ \\
\hline 16 Uruguay 4 & $1980-11$ & $\begin{array}{l}\text { "Tablita" or pre-announced crawling peg regime in place between October } 1978 \text { and November } \\
1982 .\end{array}$ \\
\hline 17 Uruguay 5 & 1991-09 & $\begin{array}{l}\text { Exchange rate band with a declining rate of devaluation introduced in December 1990. Band } \\
\text { system abandoned in June } 2002 \text {. }\end{array}$ \\
\hline
\end{tabular}

Sources: Calvo and Végh (1999); di Tella (1979); Fernández (1985); Amann and Baer (2003); and national sources.

$1 /$ According to the rule used to identify and date stabilization episodes in this paper. Year, followed by month.

2/ Central Bank of Iceland (1983, 1984). 
To carry out the exercise described above we needed to select (i) a set of relevant macroeconomic variables and (ii) an appropriate statistical method. These are discussed next.

\section{A. Monetary and Exchange Rate Dynamics in ERBS and Non-ERBS}

A successful inflation stabilization plan will lead to a reduction in inflationary expectations and, thus, an increase in money demand. The underlying exchange rate regime is a key determinant of the way in which this re-monetization takes place. Consider the following basic relationship:

$$
M \equiv C+R
$$

where $M$ is base money, $C$ is credit issued by the central bank, and $R$ stands for net international reserves held by the central bank. Ignoring valuation effects associated with changes in the exchange rate, equation (1) simply identifies the two counterparts of base money. Defining the operator $\Delta X$ as the absolute change in variable $X$ over a finite interval, we can re-write equation (1) as:

$$
1 \equiv \Delta c+\Delta r
$$

where:

$$
\Delta c_{t}=\frac{\Delta C_{t}}{\Delta M_{t}} \text { and } \Delta r_{t}=\frac{\Delta R_{t}}{\Delta M_{t}}
$$

In other words, $\Delta c$ and $\Delta r$ represent, respectively, the contributions of changes in central bank credit and net international reserves to base money growth and, thus, they add up to 1 .

Consider now the simple case - labeled Case 1 for illustrative purposes — of a 'pure' moneybased stabilization (MBS), in which the exchange rate floats freely. In this case, any change in base money during stabilization should be fully explained by an equal increase in credit, with no change in the central bank's holdings of net international reserves:

$$
\text { Case 1: } \Delta c=1 ; \Delta r=0
$$

In practice, of course, nearly-pure MBS would be characterized by values of $\Delta c$ that are both positive and close to 1 . This is true irrespective of whether the stock of nominal base money increases or decreases during stabilization.

At the other end, consider a pure ERBS. If the plan proceeds as expected, a re-monetization process should be observed whose main counterpart is an accumulation of international reserves. While domestic credit expansion can also contribute to re-monetization in this case, we assume for simplicity that it does not:

$$
\text { Case 2: } \Delta r=1 ; \Delta c=0
$$


In a more realistic setting, where there is domestic credit expansion, $\Delta r$ should be both positive and relatively close to 1 to the extent that reserve accumulation is the main driver of re-monetization. Of course, if a contraction in domestic credit is part of the stabilization plan, Case 2 will also encompass situations where re-monetization under an ERBS is characterized by $\Delta r>1$ and $\Delta c<0$ (a 'strong' version of Case 2). On the other hand, if the ERBS were not credible a sizeable loss of reserves could occur and base money could actually shrink. This would complicate somewhat the use of equation (5) as a basis for identifying de facto ERBS. To the extent that reserve losses are not met with a high degree of sterilization through an expansion in domestic credit, the ERBS would still be characterized by $\Delta r$ being both positive and relatively close to 1 . However, if nearly complete sterilization were to occur, base money could still fall in nominal terms, but only by a small fraction of the fall in reserves. In this case, $\Delta r$ is positive and higher than 1 , while $\Delta c$ is negative and higher than one in absolute value. All along, however, base money is declining in nominal terms. ${ }^{8}$

There is also the possibility that the path of credit expansion is simply inconsistent with the pre-announced path of the exchange rate (even if the plan succeeds at bringing inflation down temporarily). We can characterize an ERBS where reserves are being lost because credit expansion exceeds the increase in money demand as:

$$
\text { Case 3: } \Delta r<0 ; \Delta c>0
$$

In sum, based on this very simple behavioral rules for base money, domestic credit, and net international reserves, we have been able to detect three cases: Case 1, which can be broadly associated with a pure MBS; Case 2, which encompasses the cases of a typically successful ERBS as well as one where the plan does not lead to an increase in money demand and entails reserve losses (but these are not fully sterilized); and Case 3, which typifies an inconsistent ERBS (i.e., one that is likely to fail in the absence of corrective measures). ${ }^{9}$ Admittedly, the differences among the 3 cases portrayed here can fade in less clear-cut situations than the simple examples underlying them. For this reason, we complement the analysis with additional information. In particular, since the ratio $\Delta r$ can be positive when reserves are increasing or falling, we also look at a measure of the evolution of the level of gross international reserves held by the central bank. Finally, we also look at exchange rate volatility during the first stabilization year.

\footnotetext{
${ }^{8}$ As explained later, nominal base money did not fall during the first 12 months in any of the 53 stabilizations studied here. For this reason we did not attempt to identify cases in which the following conditions were met: a declining monetary base; $\Delta r>1 ; \Delta c<0$; and $|\Delta c|>1$.

${ }^{9}$ It is important to stress here that in our sample of stabilizations Case 3 would have to refer to those episodes in which the credit growth/exchange rate mix, although ultimately inconsistent, was able to produce a reduction in inflation that met criteria (i)-(iii). Instances where these this inconsistency led to a currency crisis and a surge in inflation would not have been picked up by our episode selection algorithm.
} 


\section{B. Classifying Episodes with Cluster Analysis}

The procedure used to classify the 53 stabilization episodes into the groups described above is $k$-means cluster analysis. This procedure selects sequentially "points" (each representing a stabilization and characterized by an array of macroeconomic variables) and places them into a predetermined $(k)$ number of clusters, or groups, by minimizing the Euclidean distance between the selected point and the emerging centroid, or mean, of the cluster centers. The process requires that each stabilization episode be characterized by a vector of variables whose patterns are expected to be distinctively different across groups. The 3 cases described in the previous section provide us with a framework consistent with $k=3$. $^{10}$

For each of the 53 episodes, we collected monthly data on the balance sheet of the central bank for a period beginning 48 months before the stabilization date $(T)$ and ending 36 months after $T .{ }^{11}$ Based on these data, we constructed monthly values for $\Delta c$ and $\Delta r$, using 12-month changes in order to avoid seasonal or abrupt movements in these rates. Each stabilization

episode $i$ beginning at time $\mathrm{T}$ was then summarized in a $(1 \times 73)$ vector: $\left[\Delta r_{T+j}^{i}\right]$ for $j=-36, \ldots$, $0, \ldots, 36$.

We must stress that in many instances lack of data prevented us from constructing $r$ in a reliable manner. Whereas data on base money was always available, in some cases data on foreign assets and/or liabilities were not. In other cases data on net domestic credit was either incomplete or unavailable. In these cases, either $c$ or $r$ had to be estimated on the basis of the available information, and the other was simply computed as a residual $(1-r$ or $1-c)$. This led to some degree of measurement error in $\Delta r$ in those instances. For this reason, and in light of the fact that the ratio $\Delta r$ could be positive when central bank reserves were rising or falling, we also collected time series for gross international reserves denominated in U.S. dollars (denoted by $G R$ and readily available from IFS) and scaled them by the level of imports in the year before stabilization $(\overline{I M}) .{ }^{12}$ These data were compiled in two different ways, as monthly changes:

${ }^{10}$ The procedure described is similar to the one used by Levy-Yeyati and Sturzenegger (2002) to classify exchange rate regimes in a general setting (as opposed to during disinflation episodes, as done here).

${ }^{11}$ The source of the data was in all cases the IMF's International Financial Statistics (IFS). However, because the latest available versions of IFS contained gaps for some episodes, we filled these gaps with data from older (printed) editions of IFS. It is entirely possible that these data are of lesser quality than that in current versions of IFS and/or that they were compiled using different methodologies. In a few cases, where data were available only quarterly; monthly observations were obtained by simple interpolation.

${ }^{12}$ By using $\overline{I M}$ as the scaling factor, we avoid fluctuations caused by the volatility of imports during the disinflation period. 


$$
\Delta g_{t}=\left(G R_{t}-G R_{t-1}\right) / \overline{I M} ; t=T+1, \ldots, T+12
$$

or, to be consistent with the frequency implicit in the computation of $\Delta r$, as deviations from the level prevailing in $T$ :

$$
\Delta \hat{g}_{t}=\left(G R_{t}-G R_{T}\right) / \overline{I M} ; t=T+1, \ldots, T+12
$$

Finally, because one would expect the exchange rate to fluctuate less in ERBS, we constructed two measures of exchange rate volatility. Because an ERBS may entail not only a fixed exchange rate but also a pre-announced rate of crawl, or even a band, we focus on measures of volatility of the depreciation rate, rather than the level of the exchange rate, and scaled the measure by the average pace of depreciation. In other words, for each episode $i$ we computed rolling coefficients of variation of the depreciation of the bilateral exchange rate vis-à-vis the U.S. dollar as follows:

$$
\rho_{t}^{i}=\frac{\sigma_{\dot{e}_{t}}^{i}}{\dot{\dot{e}}} ; t=T, \ldots, T+12
$$

where $\sigma_{\dot{e}_{t}}^{i}$ is the standard deviation of the monthly depreciation rate over the 6 month period between $t$ and $t+5$ and $\bar{e}$ is the average devaluation over the fixed 84-month period between $T-47$ and $T-36$. We then computed, for each episode, two averages of the rolling correlation coefficients: one over the first six months of the stabilization plan and the other over the first 12 post-stabilization months:

$$
\Psi^{i}(j)=\frac{\sum_{s=T}^{T+j} \rho_{s}^{i}}{j+1} ; j=6,12
$$

\section{The EXPERIMENTS ANd MAIn RESUlts}

A number of experiments were carried out using different combinations of the variables discussed in the previous section. The experiments differ in the set of variables used to characterize a stabilization episode. In a first set of experiments $\Delta r_{t}, \Delta g_{t}$ and/or $\Delta \hat{g}_{t}$ were used to identify three clusters $(k=3)$ corresponding to the cases described by equations (4) (6). In a second set of experiments, 2 clusters were constructed based on values of $\Psi(6)$ or $\Psi(12)$. As explained earlier, clustering based exclusively on measures of exchange rate volatility is aimed at splitting the sample only into ERBS and non-ERBS. Other experiments than those reported here were also carried out with results that were generally consistent with those presented here.

Before turning to the experiments, it is important to clarify some aspects related to the practical use of cluster analysis in this paper. First, all variables used in a given experiment were normalized (the sample mean was subtracted and the result was divided by the sample standard deviation) before implementing the experiments. The purpose of this is to prevent 
the clustering from being unduly influenced by differences in the magnitudes of different variables. Since interpretation of the clusters requires knowledge of the cluster means in terms of the original values of the variables, the resulting cluster centers were transformed back into the original units after each experiment was concluded. Second, meaningful clustering requires the exclusion of outliers. To deal with this problem, we imposed a rule whereby each experiment would have to be repeated until the resulting clusters had 6 or more members (slightly above 10 percent of the original sample). Clusters with less than 6 episodes were considered outliers. The admittedly arbitrary limit of 6 , however was rarely binding: in most runs, outliers were identified as clusters with only one or two members (typically, cases in which the value of the variables exceeded two or even three standard deviations around the mean). Finally, whereas all experiments were based on the selection of an a priori value for $k$, there is no guarantee that the resulting clusters will indeed be characterized by a consistent set of features that resemble the cases that motivated the selection of $k$ (i.e., the three cases described by equations (4)-(6)). Thus, whilst we focus on the values of the cluster centers in order to determine whether a given stabilization relied on the exchange rate as a nominal anchor, we may not always be able to come up to an answer to that question. Our conclusions will be based on general patterns exhibited by the cluster centers.

\section{A. Monetary Dynamics}

\section{Experiment 1}

The first $k=3$ cluster analysis was based on two variables: changes in $r$ and $\hat{g}$ in the 12-month period beginning with stabilization $\left(\Delta r_{T+12}\right.$ and $\left.\Delta \hat{g}_{T+12}\right)$. These variables provide a summary measure of movements in net and gross central bank foreign assets and, thus, give us a useful starting point for the classification of the stabilization episodes. The initial runs produced three outliers: Argentina, February 1980; Mozambique, October 1996; and Peru, April 1986. Thus, the effective number of episodes was reduced to 50 . The main results are summarized in Table 3.

Based on these results, one could argue that the first two clusters, which account for 40 of the cases, resemble the behavior of a de facto ERBS as typified in Case 2: $\Delta r$ is positive and at least one in both of them, and the positive value for $\Delta \hat{g}$ suggests that the estimated positive contribution of net reserves to base money growth was indeed accompanied by an accumulation in gross reserves during the first year of stabilization. However, important differences in magnitude exist between the first two clusters. The average values of $\Delta r$ and $\Delta \hat{g}$ in the first cluster are quite high: reserve-backed accumulation of base money accounts for nearly 300 percent of base money growth, and gross reserves held at the central bank increased by some $5 \frac{1}{2}$ months of imports. This case resembles closely the 'strong' version of Case 2, with substantial gross reserve inflows and the negative contribution of credit to base money growth reflecting possibly fiscal austerity (i.e., the accumulation of government deposits at the central bank). The second cluster has a textbook average of 1 for $\Delta r$, which suggests that domestic credit expansion played, on average, no role in re-monetization during the first 12 months of stabilization, although the average figure for $\Delta \hat{g}$ suggests only a moderate ( $1 / 2$ a month) of gross reserve accumulation. This cluster is broadly consistent with 
Case 2 as depicted by equation (4). Thus, all episodes in the first two clusters are interpreted as de facto ERBS.

Table 3. Experiment 1: Main Results

\begin{tabular}{lccc}
\hline & Cluster 1 & Cluster 2 & Cluster 3 \\
\cline { 2 - 4 } $\mathrm{N}$ & 7 & 33 & 10 \\
& & & \\
Centers & & & \\
$\quad \Delta r_{T+12}$ & 2.7 & 1.0 & -6.3 \\
$\quad \Delta \hat{g}_{T+12}$ & 5.4 & 0.6 & 0.4 \\
$\quad$ & & & \\
Averages for: & & & \\
$\quad$ History & 81.4 & 62.1 & 77.5 \\
$\quad$ Duration & 67.6 & 84.2 & 70.0 \\
$\quad$ Speed & 0.62 & 0.53 & 0.48 \\
$\quad$ Percentage of de jure ERBS & 29 & 36 & 10 \\
& & & \\
\hline
\end{tabular}

Source: authors' estimates.

The third cluster, comprising 10 stabilizations, is unclassifiable because a highly negative value for $\Delta r$ is placed in the same group with a positive value for $\Delta \hat{g}$. These two values could be reconciled if they reflected a situation in which base money was declining despite central bank purchases of foreign exchange. However, base money growth is positive in all stabilization episodes in our sample. Appendix Table 1 shows the cluster membership for this and all subsequent experiments.

Interestingly, 14 of the 15 de jure ERBS in the sample (after Argentina, February 1980, and Peru, April 1986, were excluded as outliers) fall in the first two clusters and with roughly the On the other hand, episodes in cluster 1 took place after a more protracted period of high inflation (nearly 20 additional months than those in cluster 2), and were characterized by a slightly faster pace of disinflation. While acknowledging that these are simple statistics, we note that the fact that history is higher but duration lower in cluster 1 (compared to cluster 2) same frequency. ${ }^{13}$ This could be interpreted to mean that monetary dynamics in de jure and de facto ERBS do not differ in an meaningful way. Although episodes in cluster 1 seem to resemble the 'strong' version of Case 2, they did not represent on average the most successful stabilizations as suggested by the relatively low value of duration for this group. is consistent with recent econometric findings by Hamann and Prati (2002) showing that the

${ }^{13}$ The remaining de jure ERBS, Ecuador, September 1993, could not be classified in any of the first three experiments. 
probability of preserving initial gains in disinflation is lower in cases with a longer history of pre-stabilization inflation. Furthermore, the significantly higher values of $\Delta r$ and $\Delta \hat{g}$ and in cluster 1 may be related to another finding by those authors: rapid bank credit growth fuelled by capital inflows tends to increase the probability that an initially successful stabilization plan will fail. ${ }^{14}$

\section{Experiment 2}

Unlike Experiment 1, which focused on single values of $\Delta r$ and $\Delta \hat{g}$, Experiments 2 and 3 are based on the monthly dynamics of each of those variables during the first year of disinflation. As a result, these two experiments rely on more information than Experiment 1 . Notice, however, that keeping the number of clusters fixed at 3 amounts to imposing an additional set of constraints, namely that the dynamic behavior of international reserves during the disinflation period is similar within the clusters (an admittedly restrictive assumption).

Experiment 2 attempts a $k=3$ cluster analysis using the vector $\left[\Delta r_{T+i} ; \Delta \hat{g}_{T+j}\right] i=0, \ldots, 12$;

$j=1, \ldots, 12$ for each stabilization episode. In the first three iterations, four outliers were removed from the sample (Nicaragua, August 1991; Sierra Leone, August 1992; Syrian Arab Republic, June 1988; and Lebanon, April 1988). As a result, the number of classifiable episodes in this experiment was reduced to 49.

The two panels in Figure 1 show the cluster centers for $\Delta r_{T+i} ; i=0, \ldots, 12$ and $\Delta \hat{g}_{T+j} j=1$, ..., 12. It is worth emphasizing here that, whereas $\Delta r_{t}$ tracks year-on-year monthly movements in the contribution of net foreign assets to base money growth, $\Delta \hat{g}_{t}$ represents monthly deviations in gross international reserves from a fixed point, the stabilization month (T). This complicates somewhat the interpretation of the resulting clusters. ${ }^{15}$

The first cluster, which in this case accounts for nearly half of the sample, resembles an ERBS as described in Case 2. The re-monetization process is increasingly driven by an accumulation of net foreign assets by the central bank and, although the average value of $\Delta r$ for the year is 1 , it reaches $2 \frac{1}{2}$ by the end of the period. At the same time, the cluster centers for $\Delta \hat{g}_{t}$ show an increase in gross reserves of the central bank equivalent to some 2 months of imports in the first six months, and another $1 / 2$ month during the rest of the year.

\footnotetext{
${ }^{14}$ We note, however, that if the first two clusters (both deemed de jure ERBS) are taken together, we could no longer assess whether ERBS tend to be preceded by longer history, since the remaining cluster is unclassifiable.

${ }^{15}$ The reason for not measuring $\Delta r_{t}$ as month-to-month changes or deviations from the stabilization date $T$, is the strong seasonality embedded in the series for base money and its components, which is not exhibited by the other variables used here.
} 
Figure 1. Experiment 2: Cluster Centers

$\Delta r$

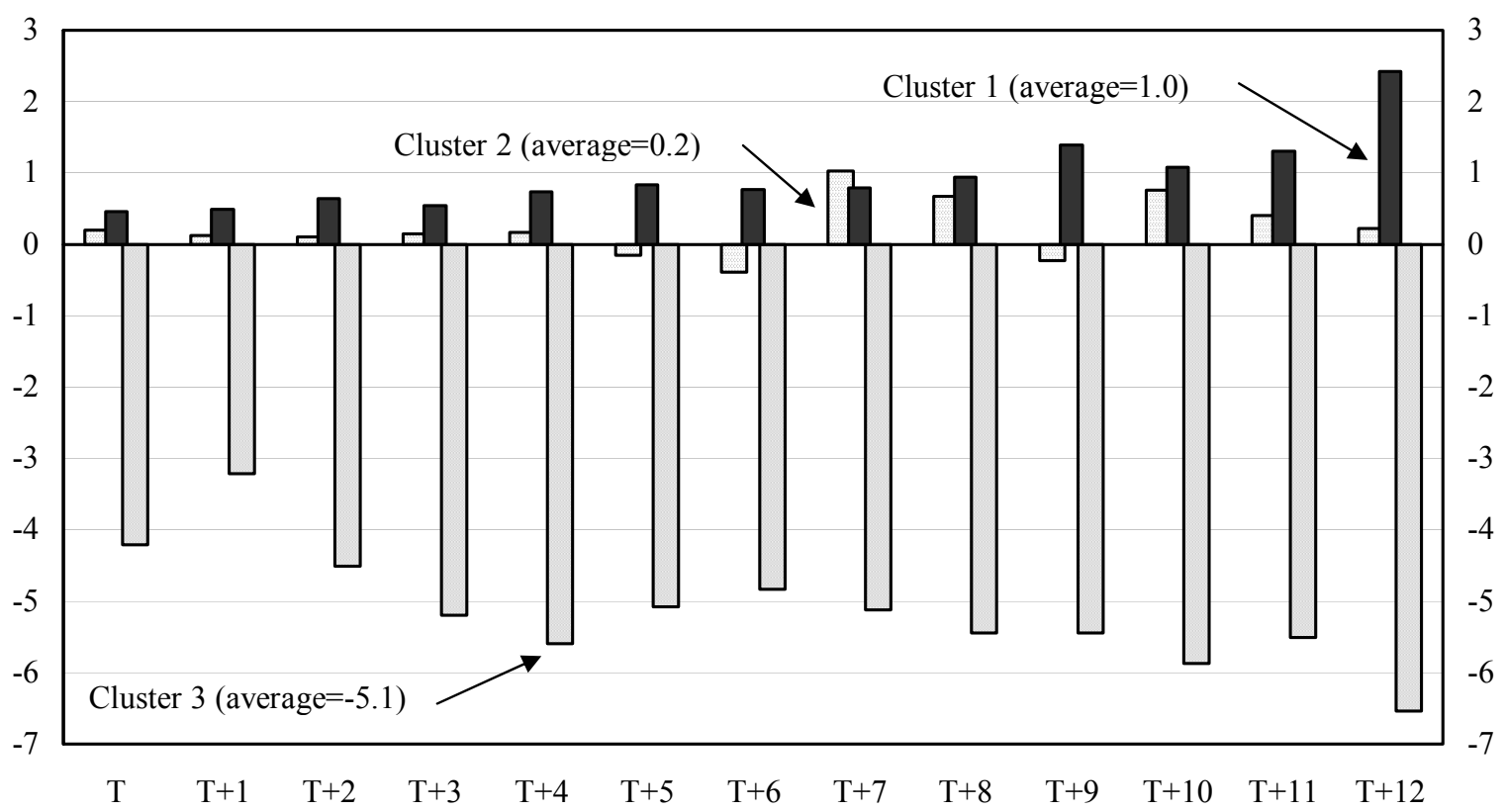

$\Delta \hat{g}_{t}$

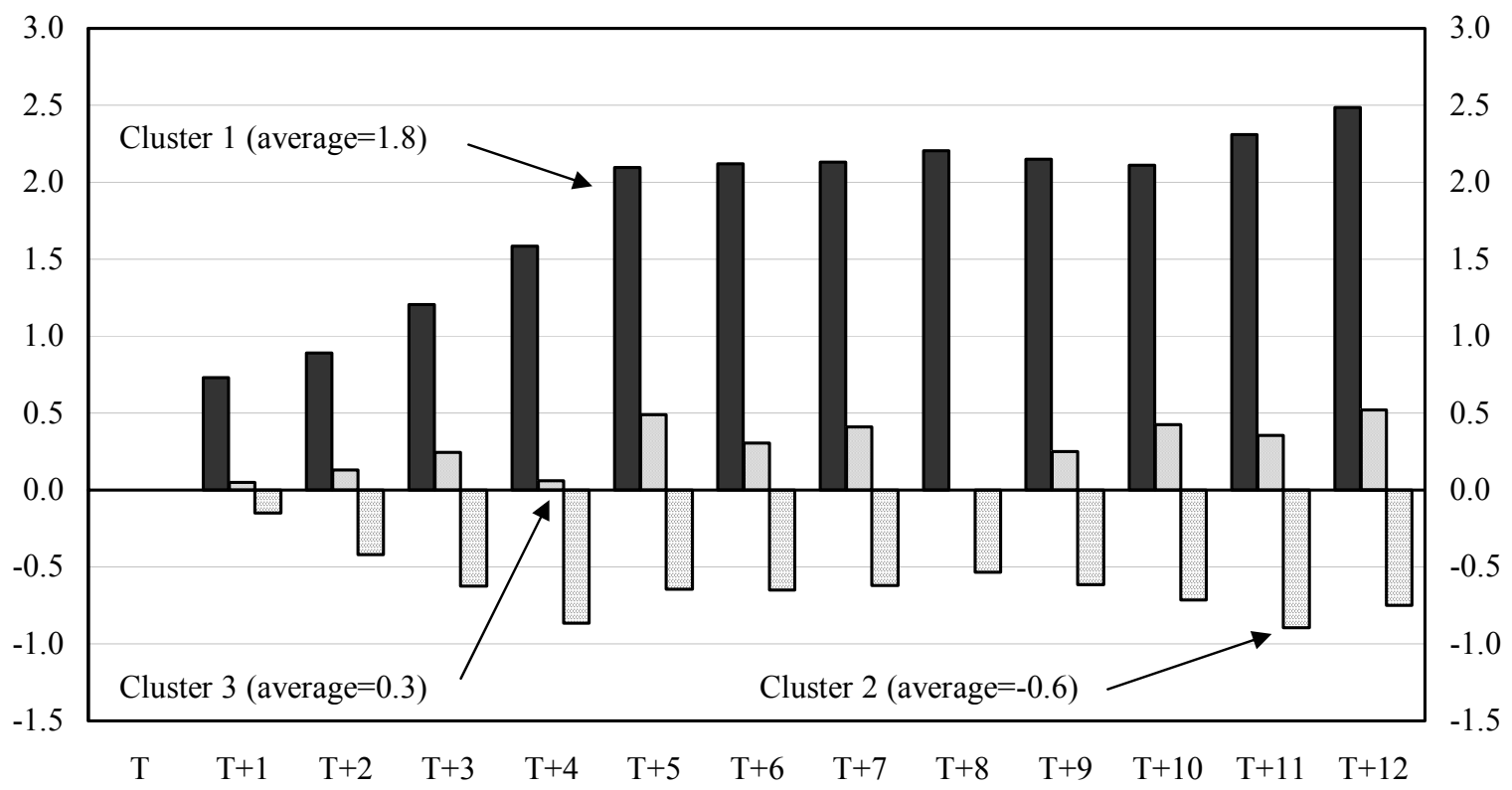

Source: authors' estimates. 
The second cluster, comprising 18 episodes, while hardly a case of a pure MBS as depicted in equation (4), does not resemble an ERBS. During the first 5 months the values of $\Delta r$ are positive but very close to zero. In the last 8 months, movements in $\Delta r$ are somewhat more erratic: on two occasions $\Delta r$ reaches a value close to one and on 3 occasions it has a slightly negative value; however, the average value of $\Delta r$ in cluster 2 is a low 0.2. Movements in $\Delta \hat{g}_{t}$ are also small (and negative), and suggest that most of the variation in gross reserves was concentrated in the first part of the post-stabilization year. There is a fall equivalent to less than one month of imports in gross international reserves in the first 4 months following the start of stabilization, but gross reserves remain broadly unchanged during the rest of the year.

As in Experiment 1, the third cluster is unclassifiable: highly negative values of $\Delta r$ are combined with positive values for $\Delta \hat{g}$ during the 12 months that follow the stabilization date. Again, these values cannot be reconciled in the sample by postulating the possibility of a strong credit crunch more than offsetting a net foreign asset-induced re-monetization, because all episodes exhibit positive growth in their stock of base money.

Table 4. Experiment 2: Main Results

\begin{tabular}{lccc}
\hline & Cluster 1 & Cluster 2 & Cluster 3 \\
\cline { 2 - 4 } $\mathrm{N}$ & 23 & 18 & 8 \\
& & & \\
Averages for: & & & \\
$\quad$ History & 69.6 & 65.9 & 90.4 \\
$\quad$ Duration & 59.7 & 84.8 & 97.9 \\
$\quad$ Speed & 0.60 & 0.42 & 0.51 \\
& & & \\
Percentage of de jure ERBS & 35 & 33 & 25 \\
& & & \\
\hline
\end{tabular}

Source: authors' estimates.

An important result emerges in Experiment 2, where, unlike in Experiment 1, the two classifiable clusters seem to represents different stabilization strategies: cluster analysis is unable to discriminate between de jure ERBS and the other stabilization plans. As shown in Table 4, the share of de jure ERBS is remarkably stable across clusters 1 and 2 (about 1/3). Table 4 also shows evidence, albeit weak, of a link between history and the adoption of a de facto exchange rate anchor: the value of history is some 6 percent higher in cluster 1. Experiment 2 also shows that duration is much lower in cases where stabilization was preceded by a more protracted period of inflation. The speed of disinflation during the first year appears to be much higher in de facto ERBS.

\section{Experiment 3}

Next, a $k=3$ cluster analysis was tried on episodes characterized by the vector $\left[\Delta r_{T+i}\right.$, $\left.\Delta g_{T+j}\right] \quad i=0, \ldots, 12 ; j=1, \ldots, 12$. The difference with the previous experiment lies in the 
way in which movements in gross reserves were defined. In the previous experiment changes in reserves were computed with respect to the stabilization date whereas in this experiment they are calculated with respect to the previous month. Five outliers were removed from the sample in two iterations (Nicaragua, August 1991; Sierra Leone, August 1992; Sudan, January 1995; Syrian Arab Republic, June 1988; and Lebanon, April 1988). Thus, the number of usable episodes was reduced to 48.

Figure 2 shows the cluster centers for $\Delta r$ and $\Delta g$. As in the previous two experiments, the first cluster (with 7 members) can be associated with a successful de facto ERBS: remonetization of the economy more than fully explained by accumulation of net foreign assets (possibly as a result of the effects on central bank net credit of fiscal adjustment). The average value of $\Delta r$ is 2.7 but this variable exhibited a clear upward trend during the poststabilization year. The behavior of $\Delta g$ is broadly consistent with this picture. With the exception of one month, $\Delta g$ exhibited positive and increasing values in the 12 months following the start of stabilization. The sum of the monthly average values of $\Delta g$ indicates an annual accumulation of gross international reserves equivalent to nearly 4 months of imports.

The second cluster resembles a non-ERBS: small movements in the central bank's net foreign assets and gross international reserves during the first 12 months of the disinflation process. The bottom panel of Figure 3 shows consistently small values of $\Delta r$, with an annual average value of 0.2 . With a few exceptions, monthly values of $\Delta g$ were also relatively small and for the year as a whole they point to an accumulation of gross reserves equivalent to only half a month of imports. Cluster 3 is again unclassifiable for the same reasons discussed in the previous two episodes.

Table 5 shows the main results of Experiment 3. As in Experiment 2, cluster analysis was unable to discriminate clearly between de jure ERBS and the other stabilization plans. In Experiment 3 the share of de jure ERBS is again broadly stable across clusters 1 and 2. Also, as in the previous experiments, the de facto ERBS in cluster 1 seem to have been preceded by longer history; however Table 5 shows no discernible evidence of a link between history and duration. Also, unlike in Experiment 2 - and Experiment 1 for the 'strong' version of case 2 laid out in equation (5) - speed is actually lower among de facto ERBS.

The first three experiments are somewhat robust in that they tended to generate two distinct groups of stabilization episodes: one that resembled successful ERBS, and one where the evidence was not always consistent with the use of an exchange rate anchor. What was less robust, however - and this is not an unusual result when cluster analysis is used - was cluster membership: of the 36 episodes that never fall into the unclassifiable group or drop out as outliers, 15 (i.e. $42 \%$ ) maintain their group membership throughout the three experiments. 
Figure 2. Experiment 3: Cluster Centers

$\Delta r$
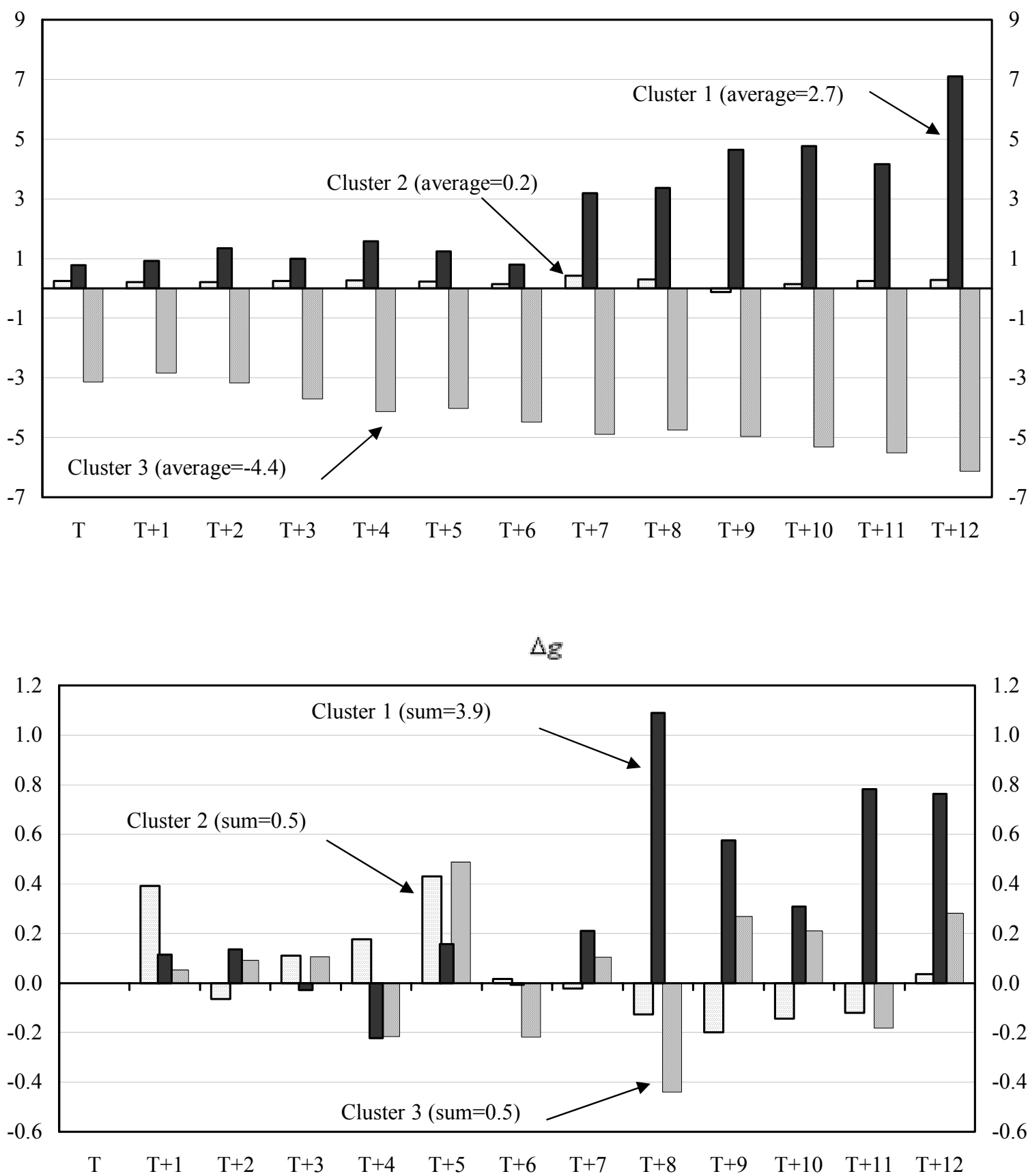

Source: authors' estimates. 
Table 5. Experiment 3: Main Results

\begin{tabular}{lccc}
\hline & Cluster 1 & Cluster 2 & Cluster 3 \\
\cline { 2 - 4 } $\mathrm{N}$ & 7 & 34 & 7 \\
& & & \\
Averages for: & & & \\
$\quad$ History & 72.9 & 67.0 & 84.3 \\
$\quad$ Duration & 70.4 & 70.8 & 103.1 \\
$\quad$ Speed & 0.45 & 0.53 & 0.61 \\
& & & \\
Percentage of de jure ERBS & 43 & 35 & 14 \\
& & & \\
\hline
\end{tabular}

Source: authors' estimates.

There was a high degree of consistency in the group of unclassifiable episodes. Of the 53 episodes, eleven were unclassifiable in at least one experiment. Of these, 6 (Brazil, January 1991; Democratic Republic of Congo, January 1995; Costa Rica, May 1983; Ecuador, September 1993; Sudan, April 1997; and Zambia, August 1990) were unclassifiable in the three experiments, and 2 (Chile, February 1975; and Sudan, January 1995) were unclassifiable in two of the three experiments. Sierra Leone, August 1992, was unclassifiable in the first experiment only, but turned out to be an outlier in the other two. It is likely that the members of the unclassifiable group probably share data problems.

Finally, the identified de facto ERBS that could be interpreted as the 'strong' version of Case 2 in equation (5) — cluster 1 in all three experiments - tend to be preceded by a longer history of inflation than the other classifiable groups (as many as 19 more months in Experiment 1, and almost 10 additional months on average across the three experiments). This may be consistent with Hamann and Prati's (2002) finding that countries with a long history of inflation are more likely to choose an exchange rate anchor for stabilization. On the other hand, the episodes in cluster 1 appear to have been less successful: while duration in clusters 1 and 2 was almost identical in Experiment 3, it was significantly shorter in cluster 1 in Experiment 1 (17 months) and Experiment 2 (25 months).

\section{B. Exchange Rate Volatility}

The following two experiments seek to classify stabilizations into two groups based on their degree of exchange rate volatility. Thus, the only discriminating factor in each of these cases will be $\Psi(6)$ and $\Psi(12)$. In principle, the experiments should produce two groups that resemble ERBS and non-ERBS. 


\section{Experiment 4}

Experiment consisted on a $k=2$ means cluster analysis based on $\Psi(12)$. During the first three iterations, five outliers were dropped (Ghana, July 1978; Iceland, March 1984; Ghana, November 1996; Guinea-Bissau, September, 1997; and Turkey, February 1986). Thus, the number of episodes was reduced to 48. Table 6 summarizes the results of this experiment. The cluster centers are 0.03 and 0.35 , which would suggest that the first cluster, characterized by much lower exchange volatility, is capturing de facto ERBS. The resulting clusters are quite imbalanced in terms of size, with cluster 1 accounting for some 41 episodes (85 percent of all cases). Interestingly, cluster 2 contains 2 episodes classified as de jure ERBS:

Argentina, November 1973, and Ecuador, September, 1993. The first case can be considered a statistical anomaly, because during this episode the rolling coefficient of variation scored zero for the first 10 post-stabilization months, but jumped subsequently as a result of the devaluation of October 1974. In the Ecuadorian stabilization, on the other hand, relatively high exchange volatility was entirely possible as the regime in place allowed intra-band fluctuations in the exchange rate.

Table 6. Experiment 4: Main Results

\begin{tabular}{lcc}
\hline & Cluster 1 & Cluster 2 \\
\cline { 2 - 3 } $\mathrm{N}$ & 41 & 7 \\
Centers & 0.03 & 0.35 \\
& & \\
Averages for: & & \\
$\quad$ History & 69.7 & 85.6 \\
$\quad$ Duration & 84.3 & 31.4 \\
$\quad$ Speed & 0.59 & 0.36 \\
$\quad$ & & \\
Percentage of de jure ERBS & 34 & 29 \\
& & \\
\hline
\end{tabular}

Source: authors' estimates.

The between-clusters differences in average history, duration and speed tend to be larger than those obtained in previous experiments; however, their relationship is not fully consistent with that observed in those experiments. The most striking difference is the fact that de facto ERBS no longer appear to be preceded by longer history. The relationships that do seem to hold in Experiment 4, however, are the negative link between history and duration (quite clear in both clusters in Table 6), and the fact that speed is higher among de jure ERBS. 


\section{Experiment 5}

The $k=2$ means cluster analysis carried out in Experiment 4 was repeated here using $\Psi(6)$ instead of $\Psi(12)$. Quite surprisingly, the results are very different (at least in terms of cluster membership of the episodes and a larger number of outliers). This suggests that in several cases, abrupt movements in exchange rates occurred after the first six post-stabilization months and that their presence in Experiment 4-where they were not deemed to be outliers-led to a marked shift in the threshold used in clustering the episodes relative to Experiment 5. Fifteen outliers were removed from the sample in five iterations, so the number of episodes in the sample was reduced to $38 .^{16}$

Some results are consistent with those of Experiment 4. The methodology produces again fairly unbalanced groups: one, with 31 members, characterized by a relatively low mean value for exchange rate volatility, and a much smaller one, with 7 members, that exhibits a much higher average volatility. This results are consistent with the notion that a very large share of all stabilizations are de facto ERBS. The results are also somewhat robust: of the 38 episodes that do not drop out as outliers in either experiment, 29 (or 76\%) are classified as de jure ERBS by both experiments. Also, every one of the five outliers in Experiment 4 was also an outlier in Experiment 5. That said, we must also stress that, while Experiments 4 and 5 place 7 episodes in the non-ERBS cluster, no member of cluster 2 in Experiment 4 is a member of cluster 2 in Experiment 5.

Table 7. Experiment 5: Main Results

\begin{tabular}{lcc}
\hline & Cluster 1 & Cluster 2 \\
\cline { 2 - 3 } $\mathrm{N}$ & 31 & 7 \\
Centers & 0.003 & 0.060 \\
& & \\
Averages for: & & \\
$\quad$ History & 60.4 & 69.0 \\
$\quad$ Duration & 95.6 & 79.5 \\
$\quad$ Speed & 0.68 & 0.55 \\
$\quad$ & & \\
Percentage of de jure ERBS & 43 & 32 \\
& & \\
\hline
\end{tabular}

Source: authors' estimates.

${ }^{16}$ Brazil, January 1991; Dominican Republic, September 1991; Ecuador, September 1993; Ghana, July 1978 and November 1996; Guinea-Bissau, August 1993 and September 1997; Iceland, January 1976 and March 1984; Lebanon, April 1988; Mozambique, October 1996; Turkey, February 1986, May 1995, and December 1998; and Uruguay, September 1991. 
Finally, the results for history, duration, and speed are fully consistent with those found in Experiment 4.

\section{DE FACTo ERBS, De JuRE ERBS, AND OUTPut Dynamics: Some Final OBSERVATIONS}

The next-to-last column of Table 8 shows a binary indicator summarizing the results of the five experiments described earlier. It was calculated as follows: for episodes found to be classifiable (or not an outlier) in at least three of the five experiments, a simple average of the scores obtained in the experiments was calculated (shown under the heading "Average"). If this average exceeded 0.5 , the episode was assigned a synthetic value of 1 and deemed to be a de facto ERBS. Nine of the 53 original episodes did not receive a final mark: six fell in the unclassifiable category in each of the first three experiments (Brazil, January 1991; Costa Rica, May 1983; Democratic Republic of Congo, January 1995; Ecuador, September 1993; Sudan, April 1997; and Zambia, August 1990); the other 3 cases (Lebanon, April 1988; Sierra Leone, August 1992; and Sudan, January 1995) were either outliers or unclassified in Experiments 1-3.

Figures 3-6 show two measures of output dynamics during disinflation, growth in per capita GDP and the output gaps, over a seven-year window (from $T-3$ to $T+3$, where $T$ is the stabilization date). ${ }^{17}$ The top panels of Figures 3 and 4 show the evolution of per capita GDP growth for all episodes. For the group as a whole, stabilizations were, on average, expansionary: per capita GDP growth is not only positive in $T$ but also has accelerated steadily since $T-3$. A deceleration begins in $T+2$, but per capita GDP growth remains positive in $T+3$. A very similar pattern is observed for the group of de facto ERBS (32 of the 44 classifiable episodes) in the second panel of Figure 3. For the non-ERBS (third panel of Figure 3), however, we do observe a different pattern, although the key result of positive per capita growth during disinflation still holds. In these cases, disinflation is preceded by relatively strong growth, which does not decelerate during the first post-stabilization year, but does so in the following two years. By $T+3$, per-capita growth is negative.

Among the de jure ERBS (16 of the 44 episodes) shown in Figure 4, we do observe a marked acceleration in per capita GDP growth in $T$ (and growth in that year is not only high but also significantly different from zero) and a deceleration thereafter. However, this does not amount to evidence of a "boom-bust" cycle: whereas growth does spike in $T$, the subsequent deceleration still entails positive per capita growth. Even if our truncation of the series at $T+3$ makes us miss a possible collapse in output immediately afterward, such collapse would have been preceded by some three years of moderately positive growth. Perhaps more important in this case is the fact that those stabilizations that did not entail a preannounced path for the exchange rate (usually treated as MBS in the empirical literature) are not characterized by a recession in $T$. Per capita GDP growth decelerates marginally during disinflation, but remains positive on average, and it tends to accelerate the following year.

${ }^{17}$ Output gaps were computed as deviations from a Hodrick-Prescott trend $(\lambda=100)$, expressed as percentages of the trend (or potential output) value. 
Table 8. Classification of Episodes

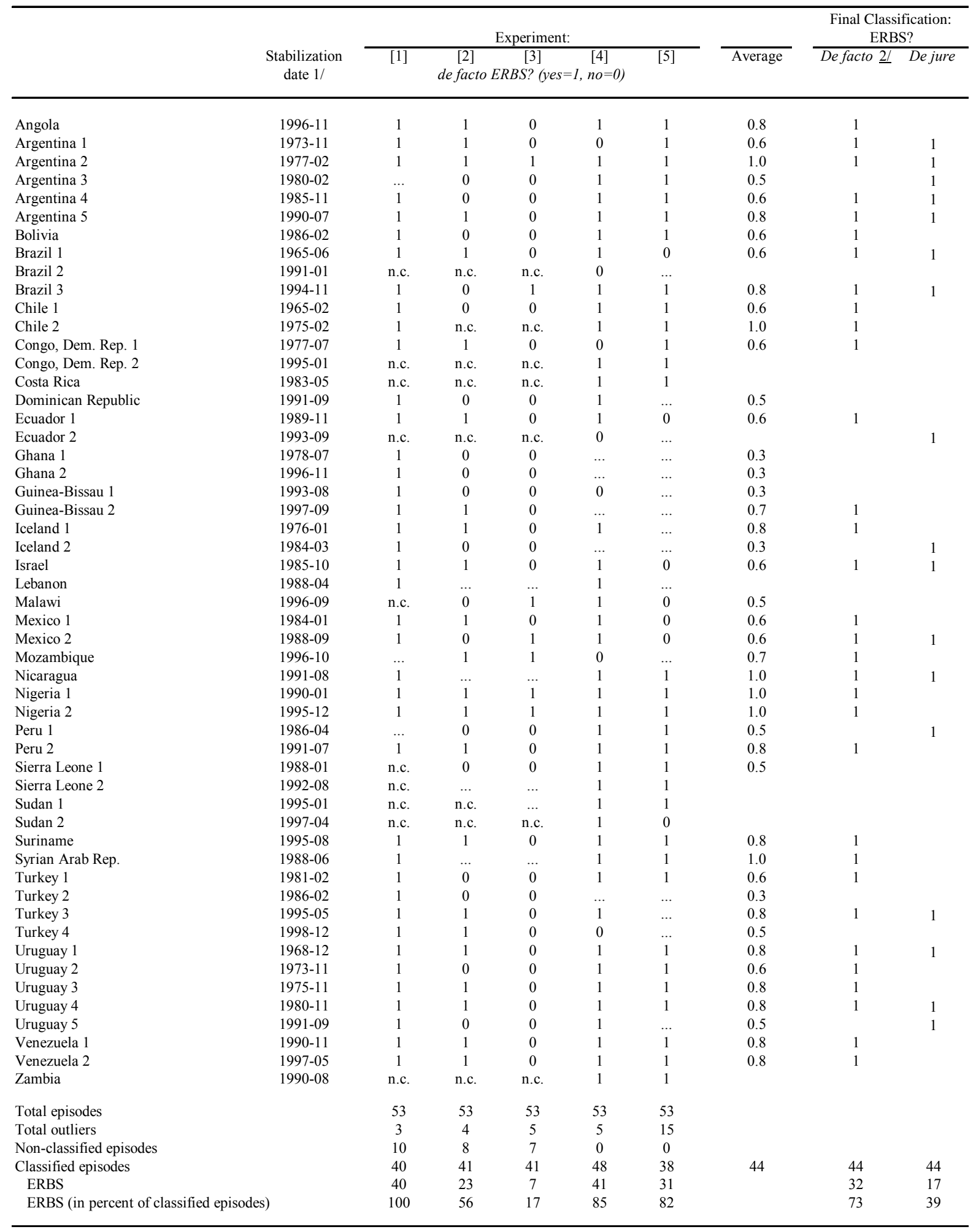

Note: 'n.c.' indicates that the episode could not be classified due to inconsistencies in the results; '...' indicates that the episode was an outlier. 1/ Dates shown indicate the year followed by the month.

2 / If a score was obtained in at least 3 experiments and the average score is greater than 0.5 . 
A comparison of the middle panels of Figures 3 and 4 suggests that, among episodes where an exchange rate anchor was, indeed, used, the preannouncement of the policy may have led to a temporary surge in domestic demand and output. This effect would presumably add to the beneficial impact of a reliquification strategy carried out through intervention in the foreign exchange market. In fact, when we exclude from the 32 de facto ERBS the 12 that are also de jure ERBS, we do not find evidence of a surge in growth at $T$, but we don't find evidence of a deceleration in per capita GDP growth either: growth is negative from $T-3$ through $T$, but fairly constant at around -2 percent from $T-2$ to $T$, and it accelerates markedly thereafter. ${ }^{18}$ The analysis of de facto but not de jure episodes also seems to suggests that the decision to preannounce an exchange rate anchor during disinflation is likely to be endogenous: the patterns of growth during the period $T-3$ to $T-1$ are very different between those groups. In de jure ERBS, growth is slightly positive right before the start of stabilization, and is close to zero in the 2 years before then. Among the de facto ERBS where an announcement was not made, growth is significantly negative throughout the prestabilization period. This result is consistent with Hamann and Prati (2002), where the choice of an anchor during stabilization is explicitly modeled. While their work did not control for the presence of not preannounced de facto ERBS, they found that higher GDP growth rates prior to disinflation increases the probability that an explicit exchange rate anchor will be used. In the same vein, Gould's (1999) finding that ERBS tend to be adopted when prestabilization prospects are better may actually point to the fact that stronger initial conditions are more conducive to a preannouncement of the strategy.

Figures 5 and 6 show the evolution of output gaps during disinflation in the various groups of stabilizations discussed earlier. The results are broadly consistent with those of Figures 3 and 4 , and also suggest that the decision to announce an exchange rate anchor is endogenous. The top panel of Figures 5 and 6 add an interesting dimension to our earlier findings: the acceleration in growth observed for the sample as a whole is mainly a recovery, as output gaps remain negative even through the stabilization year. Post-stabilization growth leads to moderately positive (less than 1 percent) output gaps. But there is considerable variation in the behavior of output gaps among the different types of stabilization. According to Figure 5, de facto ERBS take place at a time when there is considerable slack (a 2 percent gap) in the economy, whereas in non-ERBS there is no output gap in $T-1$ and, importantly, the growth exhibited in $T$ pushes the economy into a positive output gap. This may help explain the patter of growth in subsequent years: the moderately positive growth (1-1/2 percent per year) in de jure ERBS shown in the second panel of Figure 3 is consistent with a gradual narrowing of a negative output gap during that period. For the non-ERBS, in contrast, the marked deceleration in growth in years $T+2$ and $T+3$ shown in the bottom panel of Figure 3 appears to be consistent with a strong correction of a positive output gap that reaches 3 percent in year $T+2$.

${ }^{18}$ We do not show a separate figure for these cases, but one is available from the authors upon request. 
Figure 3. De Facto Classification: Growth in GDP Per Capita During Disinflation (Sample mean and 95 percent confidence interval)
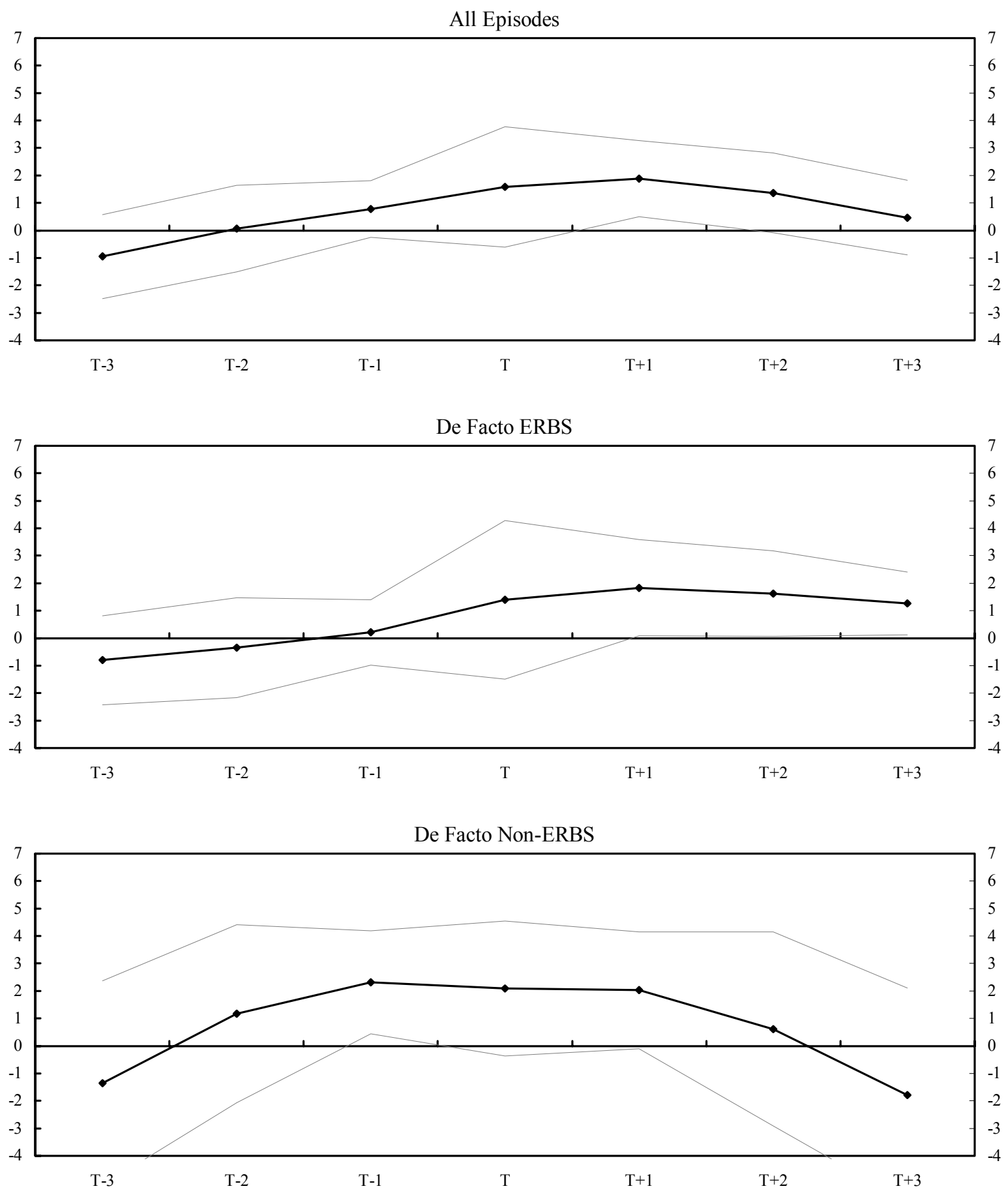

Sources: World Bank, World Development Indicators ; and authors' estimates. 
Figure 4. De Jure Classification: Growth in GDP Per Capita During Disinflation (Sample mean and 95 percent confidence interval)
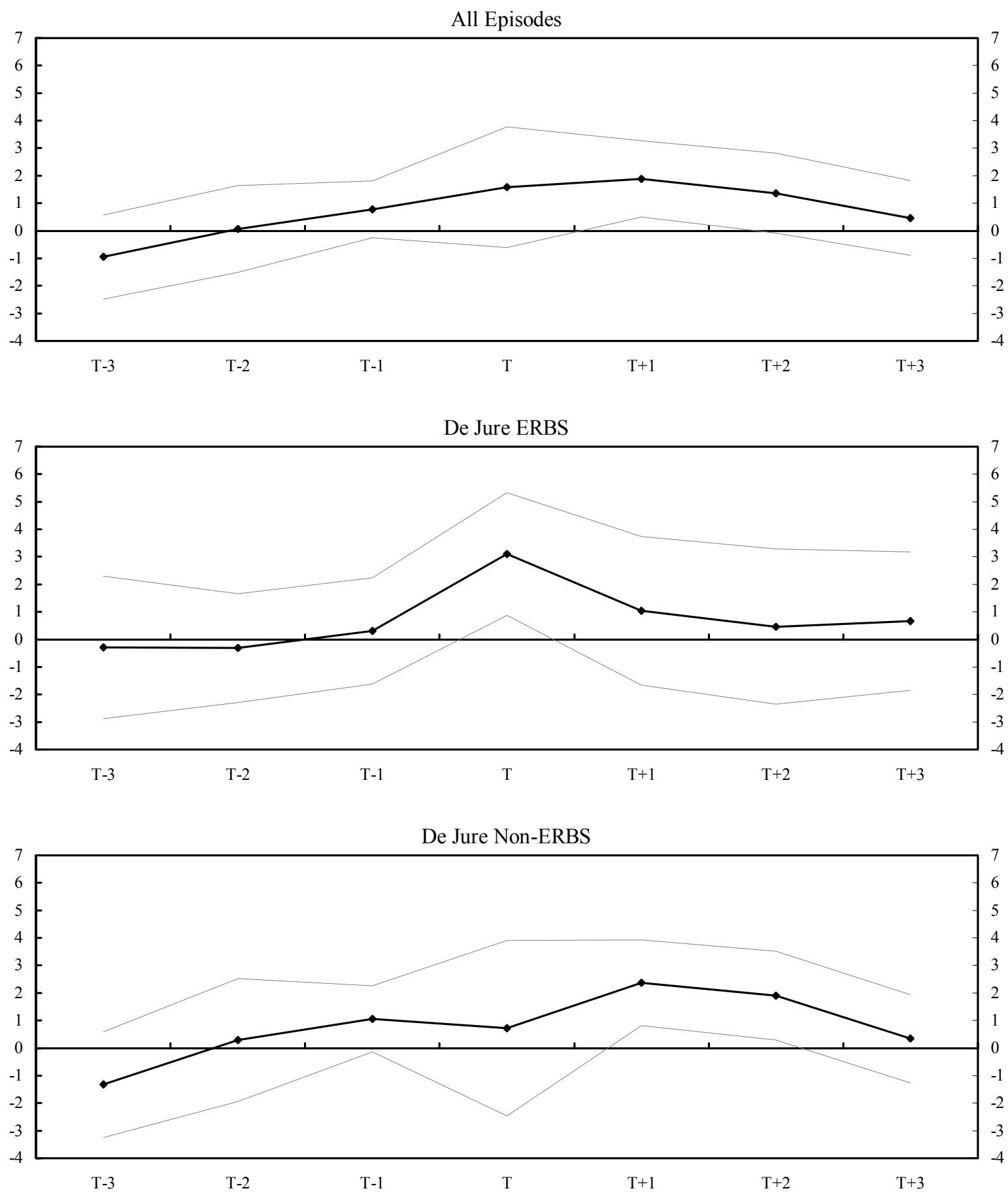

Sources: World Bank, World Development Indicators ; and authors' estimates. 
Figure 5. De Facto Classification: Output Gaps During Disinflation

(Sample mean and 95 percent confidence interval)
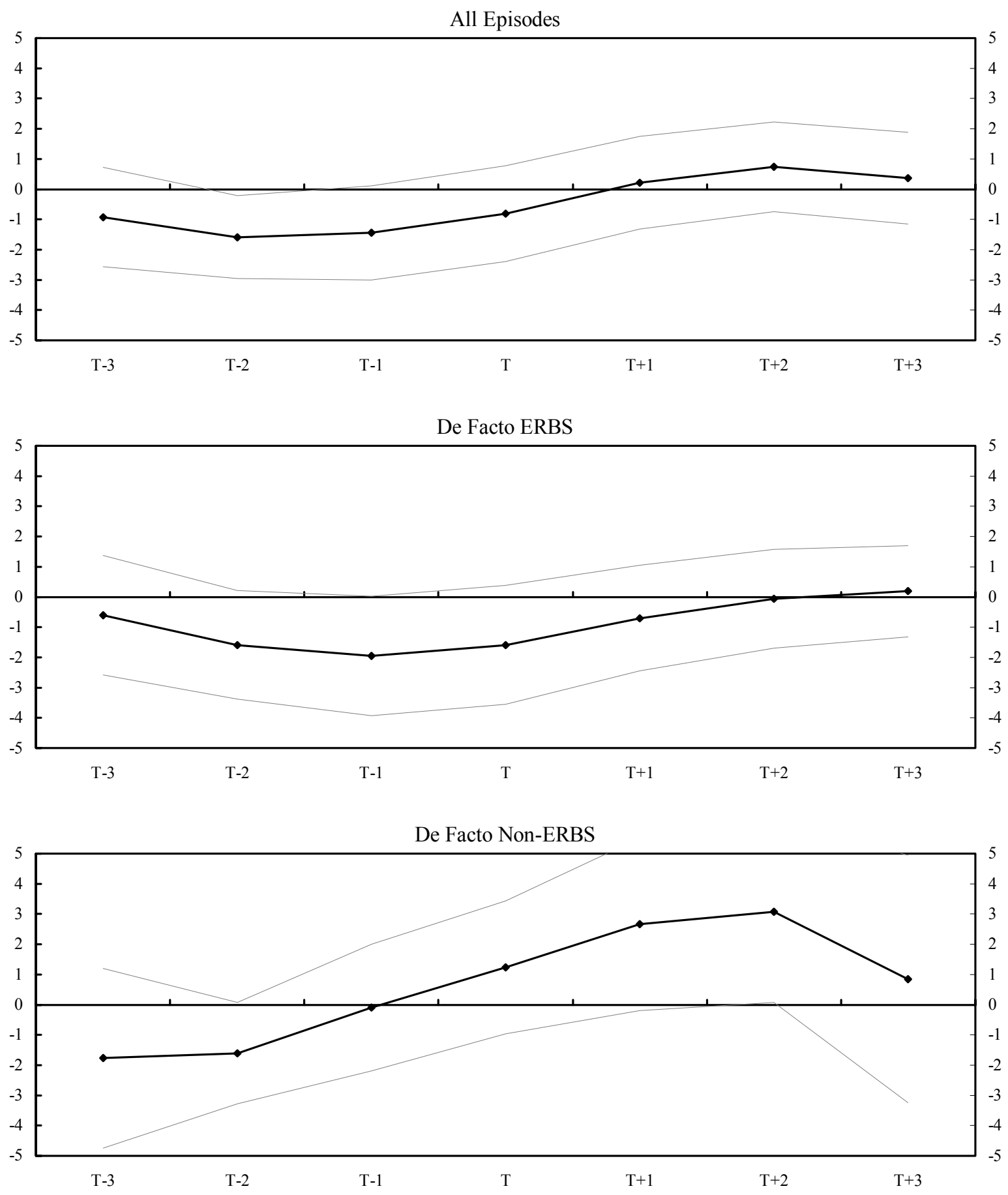

Sources: World Bank, World Development Indicators ; and authors' estimates. 
Figure 6. De Jure Classification: Output Gaps During Disinflation (Sample mean and 95 percent confidence interval)
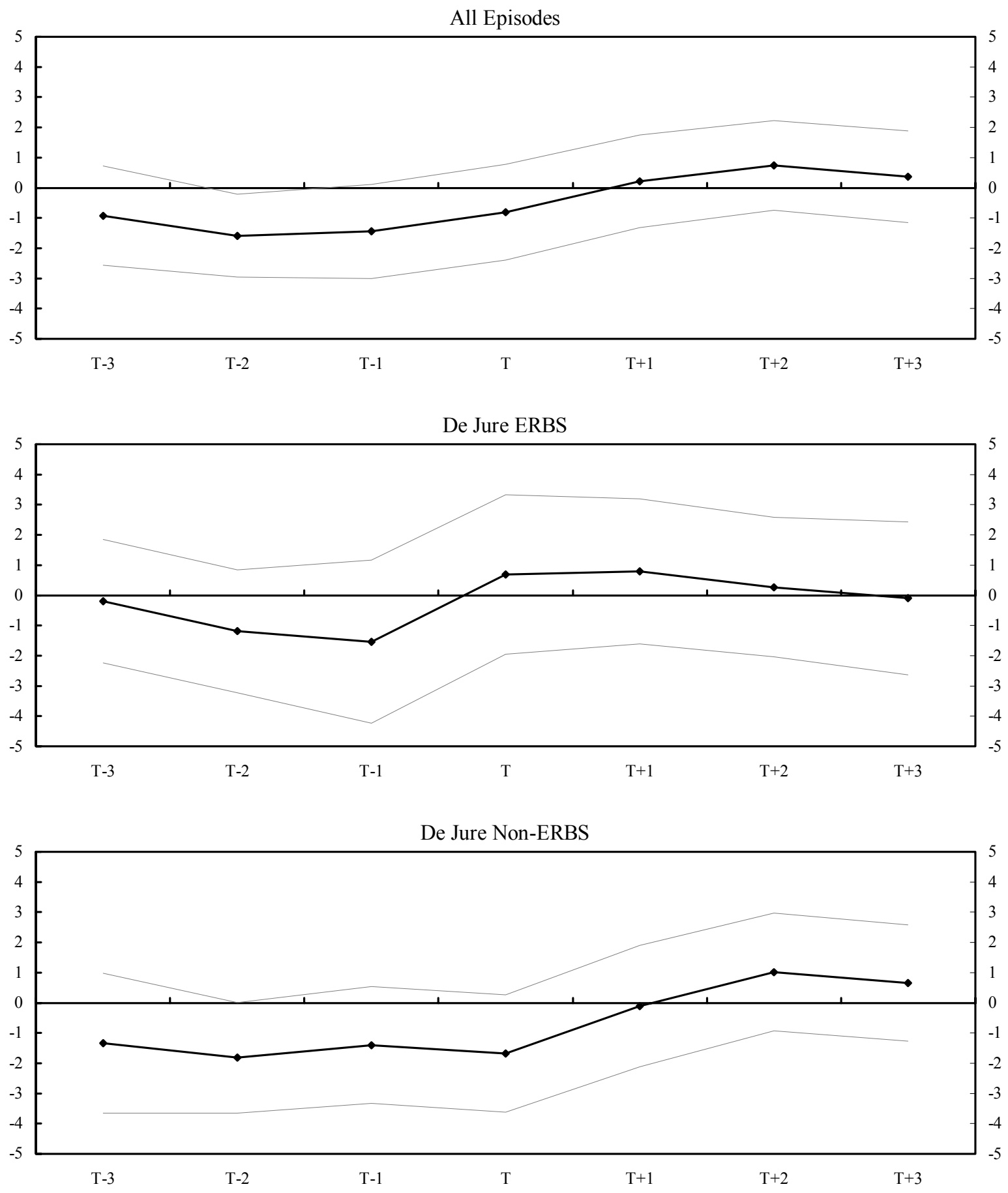

Sources: World Bank, World Development Indicators ; and authors' estimates. 
Similarly, in the case of de jure ERBS, the marked acceleration in growth in $T$ shown in the second panel of Figure 4 coincides with a swing from a negative output gap to a positive one. This, again, may explain the gradual deceleration in growth observed in the post-stabilization years, as the deceleration coincides with a narrowing of the output gap from nearly 1 percent in $T+1$ to zero in $T+3$ (second panel of Figure 6). In the case of non de jure ERBS, the absence of a strong pickup in growth in $T$ implies that output gaps remain negative until $T+1$; and the deceleration in growth observed in $T+3$ coincides once again with a correction of a positive output gap.

In sum, based on the patterns shown in Figures 3-6 (i) there is no support for the notions that de jure ERBS are characterized by a distinctive boom-bust cycle and that non-ERBS exhibit a recession as inflation falls (even though the announcement of an exchange rate anchor appears to have a marginal positive effect on output dynamics at the time of disinflation); (ii) when a de jure classification is used, we again fail to find evidence in support of the "recession now versus recession later" hypothesis; and (iii) more importantly, poststabilization growth seems to depend crucially on initial conditions, and the choice of an explicit exchange rate anchor also seems to be endogenously determined, with growth and/or the sign and magnitude of the output gap possibly playing a role in the decision to preannounce the path of the exchange rate as part of the disinflation strategy. If this were to be the case, we would have to conclude that the final answer to the question about the role of an exchange rate anchor on output dynamics can only be answered after carefully controlling for the endogeneity of the choice of the anchor as well as for other factors affecting growth more generally. This, however, goes beyond the scope of this paper and represents an area for future research.

Finally, we can also claim to have found some empirical support for Uribe's (1999) hypothesis that the reason why many empirical studies do not find MBS to be recessionary is that there are not many to begin with, because governments embarking on stabilization can always engineer a rapid monetization of the economy. In our sample of 44 classified episodes, there are more than twice as many de facto ERBS (32) as de jure ERBS (17); many of the de jure episodes, in which central bank intervention in the foreign exchange rate market helped speed up the remonetization process and prevent a recession, would have typically been classified as MBS in the empirical literature. In our view, the most likely practical way to "reliquify" the economy for countries about to embark on disinflation and where the government does not enjoy a high degree of credibility is through purchases of foreign exchange. This, of course, need not be the only way to achieve that goal. Other mechanisms, ranging from one-time traditional open market operations to direct credit lines from the central bank, may have also played a role. This would help explain the part of the puzzle that this paper could not solve: the absence of a marked recession during disinflation, even in those cases not found to be a de facto ERBS. 


\section{REFERENCES}

Amman, Edmund, and Werner Baer, 2003, "Anchors Away: The Cost and Benefits of Brazil Devaluation," World Development, Vol. 31, No. 6, pp. 1033-46.

Bruno, Michael, and William Easterly, 1995, "Inflation Crises and Long -Run Growth," NBER Working Paper No. 5209 (Cambridge, Massachusetts: National Bureau of Economic Research).

Calvo, Guillermo, and Carlos Végh, 1994, "Credibility and the Dynamics of Stabilization Policy: A Basic Framework," in Advances in Econometrics, ed. by C.A. Sims, 6th World Congress (Cambridge University Press), pp. 377-420.

Calvo, Guillermo, and Carlos Végh, 1999, "Inflation Stabilization and BOP Crises in Developing Countries," Handbook of Macroeconomics, ed. by John Taylor and Michael Woodford (Chicago: University of Chicago Press).

Central Bank of Iceland, Economic Statistics Quarterly, various issues.

Corbo, Vittorio, 1985, "Reforms and Macroeconomic Adjustment in Chile During 1974-84," World Development, Vol. 13, No. 8, pp. 893-916.

Di Tella, Guido, 1979, “The Economic Policies of Argentina's Labour-Based Government, 1973-1976," Inflation and Stabilisation in Latin America, ed. by R. Thorp and L. Whitehead (New York: Holmes and Meier).

Easterly, William, 1996, "When Is Stabilization Expansionary? Evidence from High Inflation," Economic Policy, No. 21, pp. 67-107.

Fernández, Roque, 1985, “The Expectations Management Approach to Stabilization in Argentina during 1976-82," World Development, Vol. 13, No. 8, pp. 871-92.

Fischer, Stanley. 1986. "Exchange Rate versus Money Targets in Disinflation,” in his Indexing, Inflation and Economic Policy, MIT Press, Cambridge, Massachusetts.

Fischer, Stanley, Ratna Sahay, and Carlos Végh, 2002, "Modern Hyper- and High Inflations," Journal of Economic Literature, Vol. 40, No. 3 (September), pp. 837-80.

Gordon, Robert J., 1982, “Why Stopping Inflation May Be Costly: Evidence From Fourteen Historical Episodes," in Inflation: Causes and Effects, ed. by Robert E. Hall (Chicago: University of Chicago Press).

Gould, David. 2001. "Does the Nominal Anchor Matter? Endogeneity in the Choice of a Stabilization Program," (unpublished manuscript). 
Hamann, A. Javier, 2001, "Exchange-Rate-Based Stabilization: A Critical Look at the Stylized Facts," International Monetary Fund Staff Papers, Vol. 48, No. 1, pp. 11136.

- and Alessandro Prati, 2002, "Why Do Many Disinflations Fail? The Importance of Luck, Timing, and Political Institutions," IMF Working Paper 02/228 (Washington: International Monetary Fund).

Hanson, James, and Jaime De Melo, 1985, "External Shocks, Financial Reforms, and Stabilization Attempts in Uruguay During 1974-83," World Development, Vol. 13, No. 8, pp. 917-39.

Hoffmaister, Alexander, and Carlos Végh, 1996, "Disinflation and the Recession-NowVersus-Recession-Later Hypothesis: Evidence from Uruguay,” IMF Staff Papers, Vol. 43, No. 3 (June), pp. 335-94.

International Monetary Fund, International Financial Statistics, various issues.

Kiguel, Miguel, and Nissan Liviatan, 1992, "The Business Cycle Associated with Exchange Rate-Based Stabilization," World Bank Economic Review, Vol. 6, pp. 279-305.

Levy-Yeyati, Eduardo and F. Sturzenegger, 2002, "Classifying Exchange Rate Regimes: Deeds vs. Words," (unpublished manuscript, Buenos Aires: Universidad Torcuato Di Tella) (available on the web at $\underline{\left.w w w . u t d t . e d u / \sim f_{s t u r z e n}\right)}$.

Rebelo, Sergio, and Carlos Végh, 1996, "Real Effects of Exchange-Rate-Based Stabilization: An Analysis of Competing Theories", NBER Macroeconomics Annual 1995, (Cambridge, Massachusetts: MIT Press).

Sargent, Thomas, 1982, “The End of Four Big Inflations," Inflation: Causes and Effects, ed. by Robert E. Hall (Chicago: University of Chicago Press).

Uribe, Martín, 1999, “Comparing the Welfare Costs and Initial Dynamics of Alternative Inflation Stabilization Policies," Journal of Development Economics, Vol. 59, No. 2, pp. 295-318.

Végh, Carlos, 1992, “Stopping High Inflation”, IMF Staff Papers, Vol. 39, No. 3 (September), pp. 626-95.

Veiga, Francisco José, 1999, "What Causes the Failure of Inflation Stabilization Plans?" Journal of International Money and Finance, Vol.18, No. 2 (April), pp. 169-94.

World Bank, World Development Indicators (Washington, D.C.), various issues. 
Appendix Table 1. Experiment Results: Cluster Membership

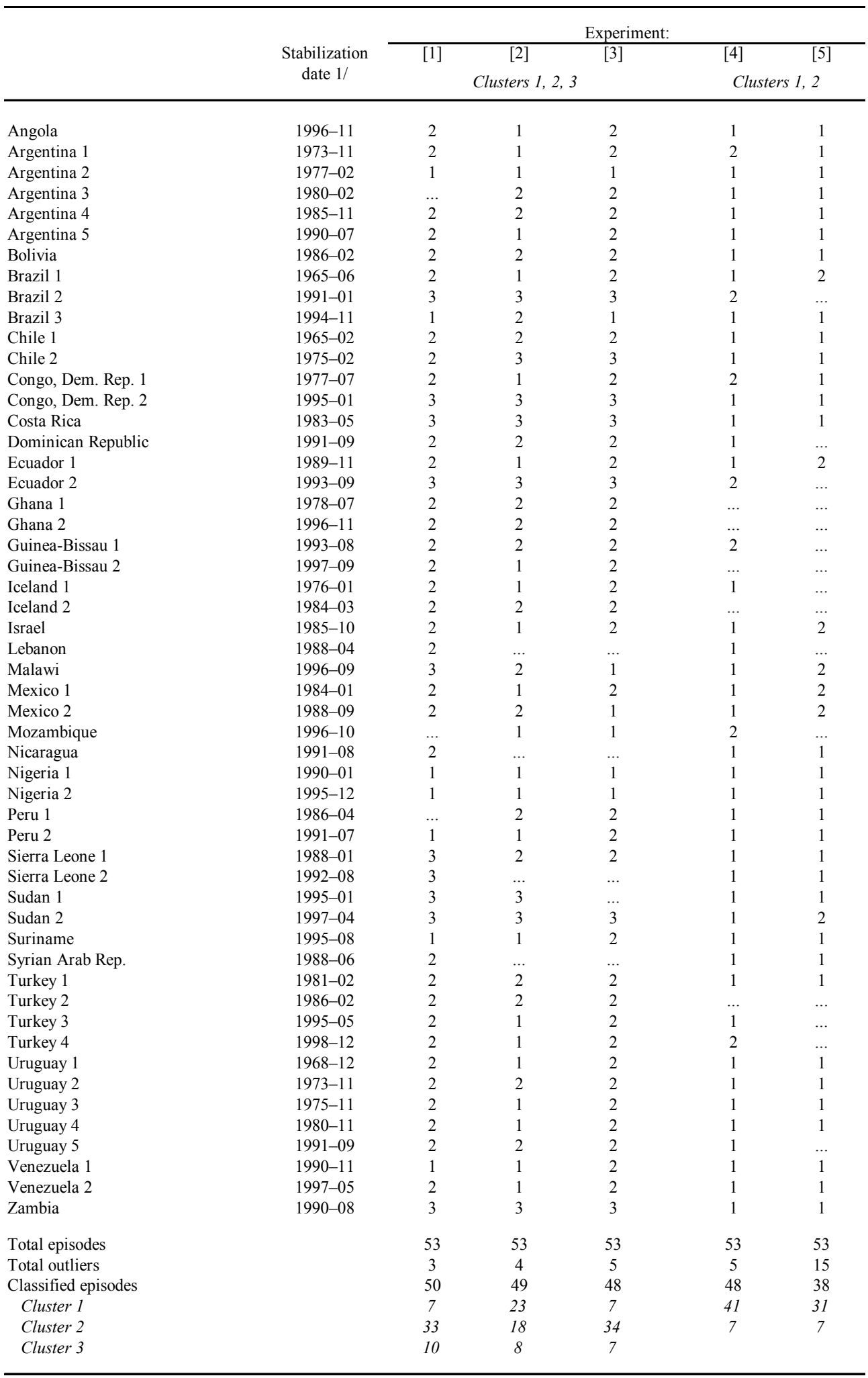

Sources: authors' estimates.

Note: 'n.c.' indicates that the episode could not be classified owing to inconsistencies in the results;

'...' indicates that the episode was an outlier.

1/ Dates shown indicate the year followed by the month. 